Georgia State University

ScholarWorks @ Georgia State University

Computer Information Systems Faculty

Publications

Department of Computer Information Systems

2007

\title{
Specifying Formative Constructs in Information Systems Research
}

Stacie Petter

University of Nebraska at Omaha, stacie_petter@baylor.edu

Detmar W. Straub

Georgia State University, dstraub@gsu.edu

Arun Rai

Georgia State University, arunrai@gsu.edu

Follow this and additional works at: https://scholarworks.gsu.edu/cis_facpub

Part of the Management Information Systems Commons

\section{Recommended Citation}

Petter, S., Straub, D., and Rai, A., Specifying Formative Constructs in IS Research, MIS Quarterly, 31(4), December 2007, 657-679. http://misq.org/specifying-formative-constructs-in-information-systemsresearch.html.

This Article is brought to you for free and open access by the Department of Computer Information Systems at ScholarWorks @ Georgia State University. It has been accepted for inclusion in Computer Information Systems Faculty Publications by an authorized administrator of ScholarWorks @ Georgia State University. For more information, please contact scholarworks@gsu.edu. 


\section{SPECIFYING FORMATIVE CONSTRUCTS IN INFORMATION SYSTEMS RESEARCH ${ }^{1}$}

By:

\author{
Stacie Petter \\ Information Systems \& Quantitative Analysis \\ University of Nebraska at Omaha \\ 1110 South $67^{\text {th }}$ Street \\ Omaha, NE 68182-0392 \\ U.S.A. \\ spetter@mail.unomaha.edu \\ Detmar Straub \\ Computer Information Systems \\ Georgia State University \\ P.O. Box 4015 \\ Atlanta, GA 30302 \\ U.S.A. \\ dstraub@cis.gsu.edu \\ Arun Rai \\ Center for Process Innovation \& Computer \\ Information Systems \\ Georgia State University \\ Atlanta, GA 30303 \\ U.S.A. \\ arunrai@gsu.edu
}

\begin{abstract}
While researchers go to great lengths to justify and prove theoretical links between constructs, the relationship between measurement items and constructs is often ignored. By default, the relationship between construct and item is assumed to be reflective, meaning that the measurement items
\end{abstract}

\footnotetext{
${ }^{1}$ Carol Saunders was the accepting senior editor for this paper. Traci Carte was the associate editor. Ron Thompson and Mark Gavin served as reviewers.
}

are a reflection of the construct. Many times, though, the nature of the construct is not reflective, but rather formative. Formative constructs occur when the items describe and define the construct rather than vice versa.

In this research, we examine whether formative constructs are indeed being mistaken for reflective constructs by information systems researchers. By examining complete volumes of MIS Quarterly and Information Systems Research over the last 3 years, we discovered that a significant number of articles have indeed misspecified formative constructs. For scientific results to be valid, we argue that researchers must properly specify formative constructs. This paper discusses the implications of different patterns of common misspecifications of formative constructs on both Type I and Type II errors. To avoid these errors, the paper provides a roadmap to researchers to properly specify formative constructs. We also discuss how to address formative constructs within a research model after they are specified.

Keywords: Formative constructs, reflective constructs, composite constructs, latent constructs, measurement models, methodology, statistical conclusion validity, Type I and Type II errors

\section{Introduction}

With the increasing popularity of structural equation modeling (SEM) techniques, information systems researchers are able to better assess both structural and measurement models. Covariance-based (e.g., techniques implemented in statistical packages such as LISREL, Amos, EQS, etc.) and componentbased (e.g., PLS) SEM allow researchers to simultaneously 
examine measurement and structural models (Gefen et al. 2000), yet researchers tend to focus on the structural model, rather than fully consider the relationship between measures and their relevant latent constructs (Jarvis et al. 2003).

This lack of concern regarding the measurement model has led some researchers to assume that all constructs should be treated alike regardless of whether a given construct is formative or reflective (Chin 1998a; Jarvis et al. 2003). ${ }^{2}$ Reflective constructs are used throughout the information systems literature for concepts such as perceived ease of use, perceived usefulness, and satisfaction. Such reflective constructs have observed measures that are affected by an underlying latent, unobservable construct (MacCallum and Browne 1993). "Changes in the underlying construct are hypothesized to cause changes in the indicators" (Jarvis et al. 2003, p. 200), meaning that respondent variations in the latent construct of perceived ease of use, for example, will cause all of its measures to reflect this change.

By way of contrast, formative constructs are a composite of multiple measures (MacCallum and Browne 1993). ${ }^{3}$ Unlike reflective measures where a change in the construct affects the underlying measures, formative constructs work differently: changes in the formative measures cause changes in the underlying construct (Jarvis et al. 2003). One example of a formative construct could be organizational performance operationalized using three measures: productivity, profitability, and market share. Each measure captures differing aspects of organizational performance, and as a result, this operationalization of the construct is formative. In this instance, the combination of these variant measures defines the construct of organizational performance.

\footnotetext{
${ }^{2}$ There is some variation in terminology in what to call these measures and constructs. Jarvis et al. (2003) use the phrases composite constructs and formative constructs when they are referring to constructs made up of formative measures. Latent variable, on the other hand, is a term that has sometimes been associated in the literature with reflective measures. Our terminology is simple and consistent with terminology use in the IS literature (Chwelos et al. 2001; Ravichandran and Rai 2000; Wixom and Watson 2001) We call both the constructs and measures either formative or reflective. We think this uniformity of terms should help convey these rather complex ideas in a more straightforward way.

${ }^{3}$ Using the words formative and construct together has generated debate. Some argue that formative constructs are not constructs, but rather composites, and the term construct should be reserved for latent variables. We believe this perception is a bit narrow in that Shadish et al. (2001, p. 506) define a construct as a "concept, model, or schematic idea" We agree with this broader definition of the term construct and, for simplicity, we refer to composite variables as formative constructs, consistent with the literature in this domain (e.g., Diamantopoulos 2006; Jarvis et al. 2003; MacKenzie et al. 2005).
}

When designing a study, the focus of the research is often on the structural paths between constructs rather than the relationship between measures and constructs (Edwards and Bagozzi 2000; MacKenzie 2001). In reality, the relationships between the constructs and the measures should also be thought of as hypotheses that need to be evaluated in addition to the structural paths (Edwards and Bagozzi 2000). When this is not done, measurement problems can conceivably arise. In the marketing literature, for instance, Jarvis et al. (2003) report that 29 percent of studies published in the top four journals during a 24-year period improperly specified formative and reflective constructs. Such measurement model misspecification can create measurement error, which in turn affects the structural model (Jarvis et al. 2003; MacKenzie et al. 2005). Because measurement error impacts the structural model, misspecification of constructs as formative or reflective increases the potential for both Type I error (a false positive by declaring a path significant when it is really nonsignificant) and Type II error (a false negative by declaring a path nonsignificant when it is really significant) in conclusions related to the structural model (Jarvis et al. 2003; MacKenzie 2001; MacKenzie et al. 2005). This potential for Type I and Type II errors due to misspecification of formative constructs affects theory development and prohibits researchers from meaningfully testing theory due to improper results (Edwards and Bagozzi 2000).

This tendency to neglect the underlying nature of the measurement model could devolve from researchers simply lacking knowledge about the nature of formative measures. A study of the marketing literature found that researchers were more likely to miscategorize formative constructs as reflective rather than improperly specifying reflective constructs as formative (Jarvis et al. 2003). This problem may not be unique to marketing in that researchers in IS are also believed to misspecify reflective and formative constructs (Chin 1998a). Furthermore, while a researcher may identify formative constructs within the underlying measurement model, this same researcher may not possess the knowledge necessary to analyze and assess the resulting model (Jarvis et al. 2003).

Even for researchers with a deeper understanding of formative constructs, another reason that formative constructs may be neglected in IS research is the additional problems a researcher faces when declaring a construct to be formative. A researcher may find that the structural model must be altered post data collection simply to analyze the model using structural equation modeling when a formative construct is present in the research model (MacCallum and Browne 1993). Indeed, if the researcher alters the structural model to accom- 
modate the formative nature of the construct by constraining or adding additional structural paths, the researcher is placed in the uncomfortable position of having to reinterpret the model and results and reconciling this with the original theory. Another problem is the dearth of guidelines to assess the validity of formative constructs (Diamantopoulos and Winklhofer 2001). Whereas there are well established validation procedures and statistical tests for determining the validity of reflective measures (Straub et al. 2004), researchers are either forced to validate formative constructs using techniques developed for reflective constructs or, sans relevant empiricism, to validate formative constructs using only theoretical reasoning.

The problem of using formative constructs becomes especially acute in covariance-based SEM where the ability to converge on a solution is extremely sensitive to the number of items in the model constructs. Item reduction techniques like indexing and item parceling are sometimes utilized to deal with this problem, but these require assumptions that are difficult to meet, including random, unbiased samples, interchangeability of items, and unidimensionality (Sivo et al. 2006). Should such assumptions be met, it would be easier to model formative constructs using covariance-based SEM (Bandalos 2002; Bandalos and Finney 2001; Hall et al. 1999; Little et al. 2002), but this is not always the case. Our primary point here is that researchers feel forced to make such difficult choices when using formative constructs in their research, and this all the more emphasizes the need for better, more widely disseminated knowledge about how to specify and use formative constructs.

Because measurement model misspecification can have a dramatic impact on one's understanding of theory (Edwards and Bagozzi 2000) and researchers do not have the necessary understanding and techniques to identify formative measures (Jarvis et al. 2003), we hope that the present paper leads to a wider comprehension of formative constructs. Our first goal is to examine the problems associated with specifying formative constructs. We do this by determining the effects of misspecification of constructs as reflective when, in fact, they are formative. This extends prior work in an important direction, namely, looking at the impact of both Type I and Type II errors. Our findings suggest that misspecifying measurement models leads to both Type I and Type II errors. Next, we illustrate the current lack of understanding about formative constructs by assessing measurement model misspecification within the IS literature. Third, we explain how scholars can properly identify and specify formative constructs. We also discuss how to address formative constructs within a research model after they are specified.

\section{Formative Versus Reflective Constructs}

\section{Review of Terminology}

Before discussing the differences between formative and reflective constructs, it is important to define the various terms that we use throughout this article. Measures, also known as indicators or items, are observable, quantifiable scores obtained through self-report, interview, observation, or other empirical means (Edwards and Bagozzi 2000). They are used to examine constructs, which are abstractions that "describe a phenomenon of theoretical interest" (Edwards and Bagozzi 2000). Constructs may be used to describe a phenomenon that is observable (e.g., task performance) or unobservable (e.g., attitude); they may focus on outcomes, structures, behaviors, or cognitive/psychological aspects of a phenomenon being investigated.

When measures are used to examine an underlying construct that is unobservable (i.e., a latent variable), the measures can be referred to as reflective indicators or effect indicators (Edwards and Bagozzi 2000). The unobservable construct, which consists of the reflective indicators and the error term for each indicator, is called a reflective construct (shown in Figure 1a) (MacCallum and Browne 1993). Indicators that determine a construct are called causal or formative indicators. Constructs comprised of these causal indicators along with a disturbance term are called formative constructs or composite variables (shown in Figure 1b) (MacCallum and Browne 1993). Structural models comprised of all reflective constructs are reflective models; however, if at least one construct within the model is formative, the model is considered to be a formative model. The differences between reflective and formative constructs will be further examined in the following section.

Note in Figure 1 that the directionality of the arrows leading from the Y's and X's to the etas is the mark of whether the construct is thought to be (and hence modeled) as formative or reflective. A way of reading this directionality is to think of the eta as "causing the indicators" in the case of reflective constructs and "being caused by the indicators" in the case of formative constructs.

\section{Differences Between Reflective and Formative Constructs}

Reflective indicators account for observed variances or covariances and reflective models minimize "the trace of the residual variances in the 'outer' (measurement) equations" 
a) Reflective Model

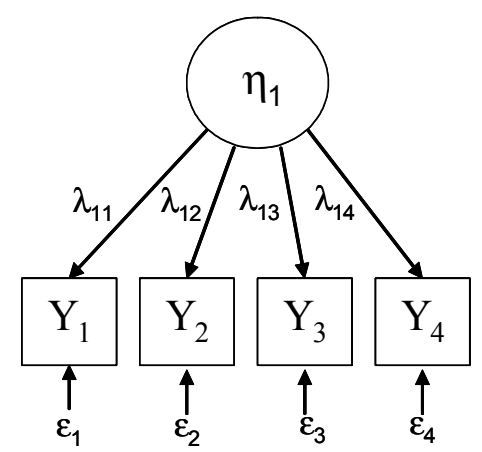

b) Formative Model

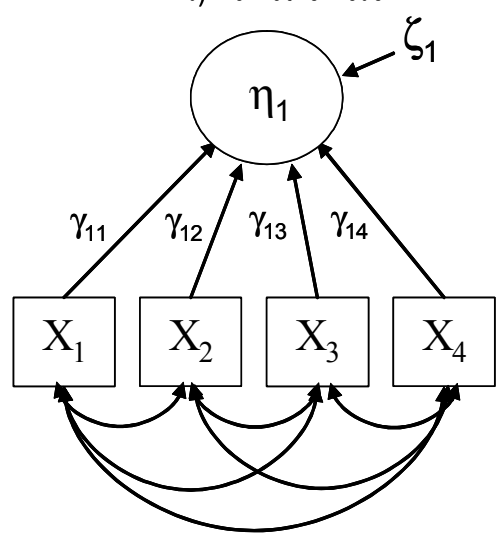

Figure 1. Diagram of Reflective and Formative Measurement Models (From K. Bollen and R. Lennox, "Conventional Wisdom on Measurement: A Structural Equation Perspective," Psychological Bulletin (110:2), 1991, pp. 305-314. Copyright $\odot 1991$ by the American Psychological Association. Reproduced with permission.)

(Fornell and Bookstein 1982, p. 442). Internal consistency is important for reflective constructs and, for this reason, Cronbach's alpha or other reliability measures are used to ensure the measures are reliable. The correlation between any two measures should be positive for reflective constructs (Bollen and Lennox 1991); however, if the reflective measurement is poorly done, the measures may not follow this predictable pattern, which some may confuse for formative measures (Edwards and Bagozzi 2000). Furthermore, reflective measures should be unidimensional, and if so, individual measures can be removed to improve construct validity without affecting content validity. Bollen and Lenox (1991) illustrate the relationship between reflective indicators and the constructs mathematically as

$$
\mathrm{Y}_{i}=\beta_{i 1} \mathrm{X}_{1}+\varepsilon_{i}
$$

Where $\mathrm{Y}_{\mathrm{i}}=$ the $i^{\text {th }}$ indicator

$\beta_{i 1}=$ coefficient representing effect of latent variable on indicator

$\mathrm{X}_{1}=$ latent variable (or reflective construct)

$\varepsilon_{i}=$ measurement error for indicator $\mathrm{i}$

Each indicator of a reflective construct is thus represented by its own equation.

Formative indicators are not used to account for observed variances in the outer model, but rather to minimize residuals in the structural relationship. Formative models minimize 'the trace of the residual variances in the 'inner' (structural) equation" (Fornell and Bookstein 1982, p. 442) and error should thus be assessed at a construct rather than at the item level. Furthermore, internal consistency or reliability is unimportant because measures are examining different facets of the construct. ${ }^{4}$ Multicollinearity, which is desired among measures for reflective constructs, is a problem for measures of formative constructs (Jarvis et al. 2003). Formative measures occasionally have patterns like reflective measures and may mislead a researcher who is looking at the empirical data alone to determine if the measures are formative or reflective (Edwards and Bagozzi 2000); therefore, it is important for a researcher to stress the theoretical relationship between measures and constructs. With formative constructs, removing a measure that focuses on a distinct aspect of the construct to improve construct validity adversely affects content validity (Jarvis et al. 2003).

Bollen and Lennox (1991) present the formative concept through an illuminating regression equation: ${ }^{5}$

$$
Y=\beta_{1} X_{1}+\ldots \beta_{n} X_{n}+\zeta
$$

\footnotetext{
${ }^{4}$ It is not uncommon for researchers to test the reliability of their formative constructs. Whereas reliability indices, such as Cronbach's alpha, may reach the threshold of 0.60 (Nunnally 1967) for exploratory work or 0.70 for confirmatory work (Nunnally 1978), the point is that meeting the requirements of these tests is not necessary and perhaps even undesirable for formative measures due to the estimation errors that can arise due to multicollinearity among formative indicators.

${ }^{5}$ Bollen and Lennox use different Greek letters consistent with LISREL terminology, but they refer to this model as a regression equation (p. 306).
} 
Where $\mathrm{Y}=$ the construct being estimated

$\beta_{\mathrm{i}}=$ beta weights for items

$\mathrm{X}_{\mathrm{i}}=$ item scores/observations

$\zeta=$ a disturbance term

Formative measures "cause" the construct and thus are assigned beta weights as in a regression formulation. One major difference between reflective and formative measures, therefore, is the extent to which a measure is required in order to completely represent the construct. With formative measures, the elimination of an item that is not duplicated elsewhere in the scale could affect whether the construct is fully represented by the measures. MacKenzie et al. (2005) state: "Dropping a measure from a formative-indicator model may omit a unique part of the conceptual domain and change the meaning of the variable, because the construct is a composite of all the indicators" (p. 712). To place this in the context of Bollen and Lennox's regression equation, each item has some nonzero beta weight associated with it. Removing a nonduplicated item will remove the beta weight contribution, however large or small it might be, and thereby reduce the variance explained.

\section{Formative Constructs vis-à-vis Multidimensional Constructs}

Another related concept associated with formative constructs is that of multidimensional constructs. Multidimensional constructs are constructs with more than one dimension, and each dimension can be measured using either reflective or formative indicators. These multiple dimensions "are grouped under the same multidimensional construct because each dimension represents some portion of the overall latent construct" (Law and Wong 1999, p. 144).

One approach to understanding multidimensional constructs is to contrast them with unidimensional constructs. Reflective constructs should, by definition, be unidimensional in that all of the measurement items are measuring the same aspect of the unobservable construct while multidimensional constructs are capturing multiple dimensions. In fact, unidimensionality is a key assumption within covariance-based SEM for reflective constructs.

Formative constructs are an extreme example of multidimensional constructs. In this case, measurement items are designed to tap into the different subconstructs and multicollinearity is safeguarded by ensuring that the items do not tap into the same aspects. Rather, one measurement item is used for each dimension or subconstruct, which, in turn, has a formative relationship with the construct. For example, earlier we stated that oganizational performance can be an example of a formative construct if it is operationalized using one measure each for profitability, productivity, and market share. Conceptually, this example could be considered a multidimensional construct that is comprised of three subconstructs (i.e., profitability, productivity, and market share) with one measurement item for each subconstruct (see Figure 2a). While this construct would be conceptualized as a multidimensional construct, it would be modeled empirically as a formative construct (see Figure 1b). If a researcher should be interested in capturing additional aspects of organizational performance, multiple items for each subconstruct could be used (see Figure 2b). These measures could be formatively or reflectively related to each subconstruct (MacKenzie et al. 2005).

While formative constructs are an extreme example of a multidimensional construct, we would like to argue very explicitly that not all multidimensional constructs are formative. An alternative is a multidimensional construct that has a formative relationship with subconstructs, yet the subconstructs consist of reflective items (e.g., see Figure $2 b$ ). Furthermore, it is also possible for the construct to have some subconstructs measured using reflective items with others using formative items and/or a mix of both formative and reflective paths between the construct and subconstructs (MacKenzie et al. 2005).

The choice to model and analyze a construct as unidimensional (i.e., reflective), formative, or multidimensional depends largely on the construct under study and "the generality or specificity of one's theoretical interest" (MacKenzie et al. 2005, p. 713). A complex construct that is the main topic of study may deserve to be modeled as a multidimensional construct so as to permit a more thorough measurement and analysis. Developing a multidimensional construct that has a formative relationship between the construct and subconstructs (see Figure 2b) should occur when multiple subconstructs and measurement items are necessary to fully capture the entire domain of the construct.

When measuring and analyzing a multidimensional construct, it is common practice among researchers to collapse the subconstruct items into a one-dimensional construct. This practice should be carried out cautiously as it can adversely impact validity of measures. For example, a construct measured in a similar manner to that of Figure $2 b$, is comprised of subconstructs with reflective items, and relationships between the subconstructs and the construct under study are formative. Evaluating the construct as a first-order unidimensional construct and including all of the items from each subconstruct as a single reflective construct produces a construct that is not 


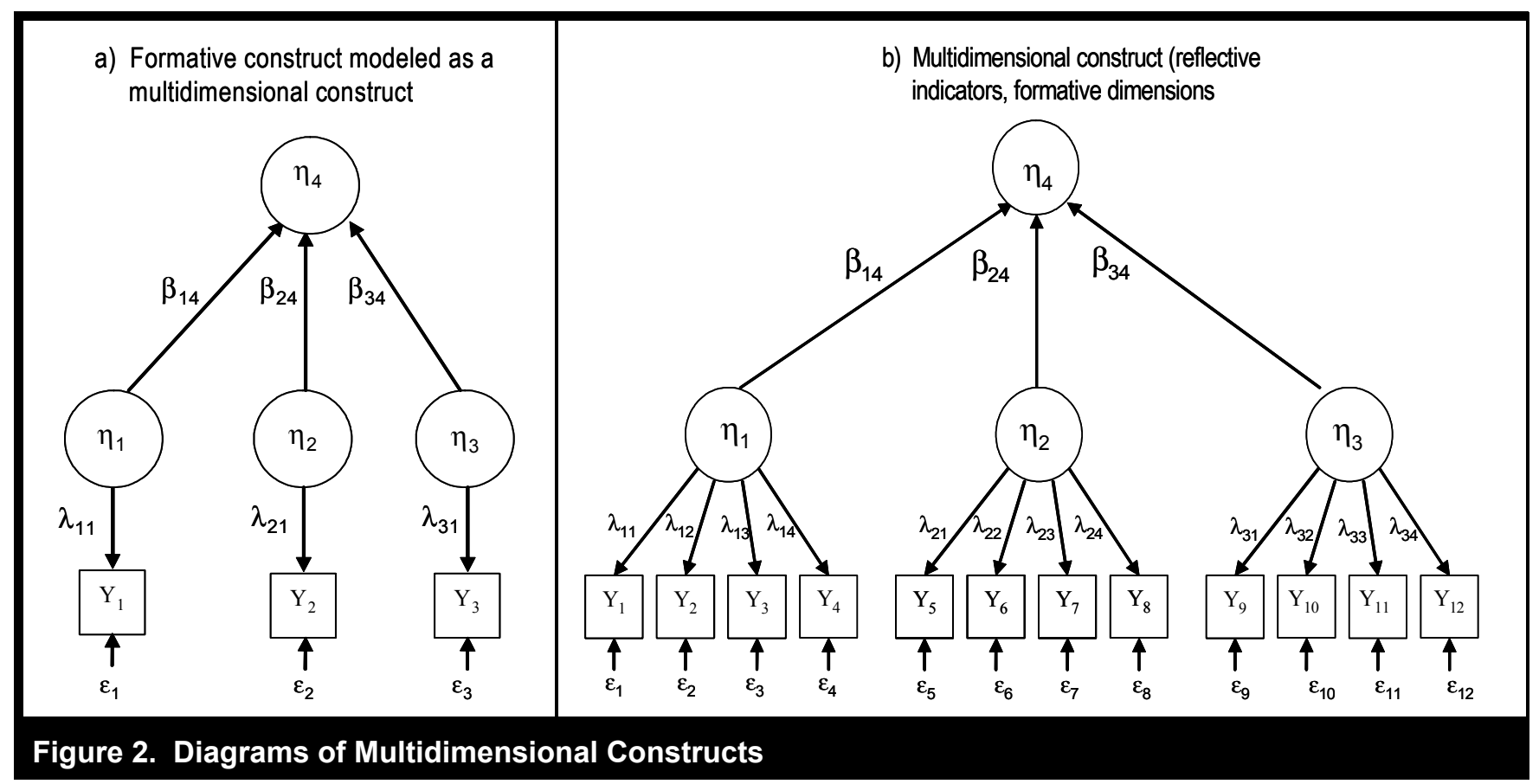

unidimensional because the items making up the construct are actually measuring three different aspects of the construct. Alternatively, some researchers may specify the construct as a first-order multidimensional construct in that aggregate measures for each of the subconstructs are specified as formative indicators (thus analyzing the construct in a way similar to Figure 2a). These approaches to collapse a higher-order multidimensional construct into a single construct can compromise validity and lead to measurement problems.

Given our discussion, researchers need to make a distinction between the order of the construct (first- or second-order) and its dimensionality. While multidimensional constructs provide the ability to increase granularity and detail on different aspects of a construct, the number of measures needed increases as does the complexity of analysis. Given this trade-off, it is important for researchers to understand the different choices available when investigating and specifying a given construct in a research model.

\section{Misspecification of Formative Constructs}

\section{Past Evaluation}

Researchers with an understanding of formative constructs may decide to avoid their use in theoretical models. Although the underlying statistics in partial least squares analysis allow it to readily handle formative measures (Gefen et al, 2000), it has historically been more difficult to employ formative measures when analyzing data via covariance-based SEM approaches (Chin 1998a). There is also the perception that formative constructs are needlessly complicated and offer little value to a theoretical model over reflective constructs (Howell et al. 2007). Researchers with this view of formative constructs have chosen to convert formative constructs into decomposed models or have measured these constructs reflectively.

Decomposed models remove the formative structure and allow reflective subconstructs or individual items to be directly related to other constructs within the model. Figure 3 illustrates how to decompose a formative construct within a research model. So why should we not decompose all formative constructs? First, decomposition results in larger models and thereby a loss in parsimony. Given that many IS models are already complicated, this may not be a viable option in most cases. Parsimonious models can provide abstractions that generate insightful explanations about complex phenomenon. Second, the decomposed model may have different theoretical implications when compared to the formative model. Third, and finally, drawing inferences at higher levels based on analysis of decomposed models can result in atomistic fallacy (Roux 2002). Relationships that hold, or do not hold at lower units of measurement and aggregation, may not hold at the higher levels. 


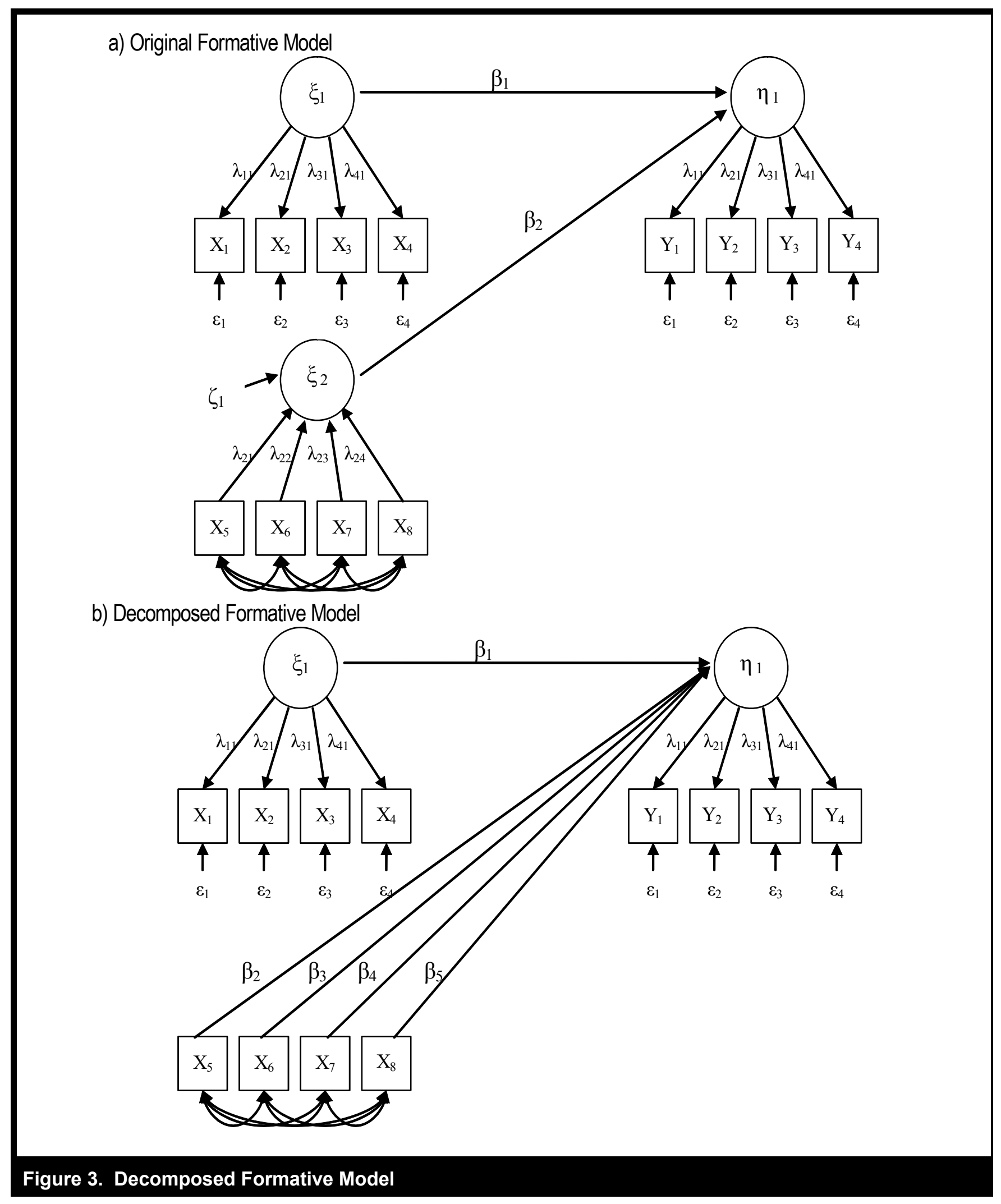


Another "remedy" that researchers may choose rather than foregoing the use of formative constructs is to simply model the construct as reflective, rather than formative. There is growing evidence, though, that this misspecification of the construct can create bias in the structural model. Some of this evidence we present below.

Jarvis et al. (2003) performed a simulation to determine the ramifications of misspecifying formative constructs as reflective. In their study, these authors examined the effects of the structural model when an exogenous formative construct was misspecified as reflective and when an endogenous formative construct was misspecified as reflective. The inter-item correlations among the items in the formative construct were modeled at $0.1,0.4$, and 0.7 to determine if the strength of correlations among formative constructs affected structural paths. Structural paths emanating from both the misspecified exogenous and endogenous formative construct have large upward biases; however, the path leading to a misspecified endogenous formative construct has a downward bias. ${ }^{6}$

MacKenzie et al. (2005) also performed a simulation to determine the ramifications of misspecifying formative constructs as reflective. This simulation was comprised of two formative constructs and examined the effects when the exogenous construct was misspecified, when the endogenous construct was misspecified, and when both constructs were misspecified. The simulation varied sample sizes (i.e., small 125 , medium -500 , and large -875$)$, inter-item correlations (i.e., weak -0.20 , moderate -0.50 , and strong -0.80 ), and structural relationship between constructs (i.e., weak -0.10 , moderate -0.30 , and strong -0.50 ). Consistent with the results of Jarvis et al., there was a large upward bias in the structural parameter estimate when the exogenous construct was misspecified (429 percent higher!), a downward bias when the endogenous construct was misspecified ( 84 percent lower), and a slight downward bias when both constructs were misspecified (18 percent lower).

\section{Misspecification of Formative Constructs: Further Investigation}

Whereas Jarvis et al. showed that bias can occur when formative constructs are misspecified as reflective, their study does not provide evidence regarding how these biases affect the statistical significance of the parameter estimate. MacKenzie et al., however, did examine the effect of misspecification on Type II error (i.e., the likelihood of stating there is no relationship between constructs when there is one). Type II error

\footnotetext{
${ }^{6}$ See Figure A1 in Appendix A for a diagram of these structural models.
}

did not occur when only the exogenous construct was misspecified, but did occur in 19 percent of simulations when the endogenous construct was misspecified and 18 percent of simulations when both constructs were misspecified. These authors determined higher standard errors for the parameter estimate were the primary cause of Type II error when both constructs were misspecified and a decrease in the parameter estimate was the reason for Type II error when only the endogenous construct was misspecified.

Although MacKenzie et al. do provide evidence of Type II error, there is currently no evidence about Type I errors when a formative construct is misspecified as reflective. MacKenzie et al.'s simulation used a very simple structural model, and, therefore, we wanted to verify their results using the larger structural model used by Jarvis et al. For these reasons, we replicated and extended Jarvis et al.'s simulation.

The purpose of our extension is to answer the following questions:

(1) Does the downward bias in parameter estimates lead to Type II error, meaning a statistically significant path between constructs is found to be nonsignificant, in larger structural models?

(2) Does the large upward bias in parameter estimates lead to Type I error, meaning paths are labeled as statistically significant when there is actually no relationship between the constructs?

If the statistical significance of the parameter estimates is affected by misspecifying formative constructs, then incorrect theoretical conclusions will result.

In all simulations in Jarvis et al., MacKenzie et al., and our extended work, misspecified endogenous formative constructs result in a downward bias in the structural paths leading into them. ${ }^{7}$ In our extension, we found that the significant path leading to the misspecified formative construct became nonsignificant (meaning there is low statistical power and a Type II error has occurred) when the formative construct is endogenous and (1) the inter-item correlations among the formative items are moderate (i.e., 0.4) and the sample size is low (i.e., 250) or (2) the inter-item correlations among the formative items are high (i.e., 0.7). This finding implies that misspecifying endogenous formative constructs as reflective reduces the statistical power of the model. This type of misspecification yields false negatives since it finds no statistical

\footnotetext{
${ }^{7}$ See Appendix A for a discussion of the simulation, the models used for the simulation, and the results.
} 


\begin{tabular}{|c|c|c|}
\hline Error & Conditions for Occurrence & Identification of Error \\
\hline Type I & $\begin{array}{l}\text { The following criteria must be met for Type I error to occur: } \\
\text { - Formative construct is endogenous } \\
\text { - Structural path emanates from formative construct } \\
\text { - Sample size is high (i.e., 500) } \\
\text { - Moderate to high correlation among formative measures } \\
\text { (i.e., } 0.4 \text { or higher inter-item correlations) } \\
\text { - Can occur regardless of whether the model is specified } \\
\text { correctly (i.e. formative) or incorrectly (i.e., reflective). }\end{array}$ & $\begin{array}{l}\text { To determine if a Type I error has occurred, ask } \\
\text { the following: } \\
\text { - Where is the potential formative construct in } \\
\text { my model? Is it endogenous? } \\
\text { - Is my sample size large? } \\
\text { - Do I have moderate to high inter-item } \\
\text { correlations? } \\
\text { - What is the parameter estimate for structural } \\
\text { paths emanating from the correctly specified } \\
\text { formative construct? Are they particularly } \\
\text { small? Do they have any practical } \\
\text { significance? }\end{array}$ \\
\hline Type II & $\begin{array}{l}\text { The following criteria must be met for Type II error to occur: } \\
\text { - Formative construct is endogenous } \\
\text { - Structural path leads to formative construct } \\
\text { - Sample size is low (i.e., } 250 \text { ) } \\
\text { - Moderate to high correlation among formative measures } \\
\text { (i.e., } 0.4 \text { or higher inter-item correlations) } \\
\text { OR } \\
\text { - Formative construct is endogenous } \\
\text { - Structural path leads to formative construct } \\
\text { - Sample size is high (i.e., } 500 \text { ) } \\
\text { - High correlation among formative measures (i.e., } 0.7 \text { or } \\
\text { higher inter-item correlations) }\end{array}$ & $\begin{array}{l}\text { To determine if a Type II error has occurred, ask } \\
\text { the following: } \\
\text { - Where is the potential formative construct in } \\
\text { my model? Is it endogenous? } \\
\text { - Do I have moderate to high inter-item } \\
\text { correlations? } \\
\text { - What is my sample size? }\end{array}$ \\
\hline
\end{tabular}

relationships between antecedent constructs and a misspecified endogenous construct, even when a statistical relationship does actually exist between them.

The simulation performed by Jarvis et al. contained all significant paths; therefore, the models examined by Jarvis et al. could only be used to determine if Type II error occurs with the misspecification of formative constructs. To detect if Type I error can occur due to mismodeling, we performed an additional series of simulations on structural models that contained a nonsignificant path (with a magnitude of 0.03). As in the prior simulation, there were similar patterns of upward bias in the parameter estimates when the exogenous formative construct was misspecified as reflective, and this bias led to Type I errors. The simulation revealed that Type I error occurs when (1) the formative construct is endogenous, (2) the sample size is large (i.e., 500), and (3) the inter-item correlations among the formative items are moderate to high (i.e., 0.4 to 0.7 ). The surprising finding from our series of simulations is that Type I error can occur regardless of whether the formative construct is specified correctly or not. However, when the formative construct was correctly speci- fied and the path was statistically significant, the practical significance of the parameter estimate was minimal, thus suggesting to the researcher that a problem may exist with the parameter estimate.

Table 1 summarizes the conditions associated with Type I and Type II errors. This table also provides a list of questions for researchers to ask themselves should they suspect Type I or Type II error is present. The danger of Type I error is that we, as researchers, may build new theories and models based on prior research that finds support for a given relationship that does not actually exist. This may affect the implications of our research for both academia and practice. The danger of Type II error is that some interesting, valuable research may not be published if many of the relationships within the model are found to be nonsignificant. Studies with interesting insights may be published to a smaller audience in second-tier journals or not at all because one or more constructs were misspecified. In addition, given the increasing complexity of IS models with multiple hypotheses, in these large models, one or more paths may be nonsignificant, even though theory suggests otherwise. These findings may be published in top- 
tier journals because a large number of hypotheses are significant. As with Type I error, the misspecification may lead researchers to create different research models and generate different insights and implications than what reality actually suggests. Given the implications and likelihood of obtaining either Type I or Type II error for mismodeled formative constructs, it is important that researchers know how to identify formative constructs in their research models.

\section{Measurement Model Misspecification in IS Research: Empirical Evidence}

The preceding discussion about misspecification would be perhaps an interesting academic exercise if specification of models in IS research were in the realm of possibility, but did not actually occur. In this case, the contribution of the current paper would be limited to a set of circumstances that IS researchers should be aware of, but were not a problem at the moment. To determine if the misspecification of formative constructs is indeed a problem in the IS field, we conducted a review of recently published literature. To assess the prevalence of measurement model misspecification, we examined articles published in a 3-year period between 2003 and 2005 in two highly regarded IS journals, MIS Quarterly and Information Systems Research. Although this is a relatively small sample of the IS literature, we reasoned that if we found construct misspecifications within this small sampling of closely reviewed manuscripts in the highest quality journals in the field, then it is reasonable to assume that measurement model misspecification is a problem in all IS journals.

To conduct this review, we identified all empirical papers with measurement models consisting of constructs measured by two or more items. Simulations, studies consisting only of single item measures, or papers that did not report measurement items within the text or an appendix were not included in the analysis. This yielded a list of 39 papers for analysis.

To begin, we performed a pilot test of our coding procedures. Next we examined measurement items for each construct. ${ }^{8}$ The coders were the researchers, and each coder specified whether the author modeled the construct as formative or reflective as well as whether the construct should have been modeled as formative, reflective, or mixed. Recognizing that coding constructs as formative or reflective is a subjective process, we decided to create a "mixed" category. As we

\footnotetext{
${ }^{8}$ Any items purged from the construct, but mentioned in the paper, were eliminated from consideration.
}

examined the literature, we found constructs that were dominantly reflective or dominantly formative; however, some constructs seemed to consist of some formative and some reflective items. We classified these constructs as mixed to denote constructs that were "on the fence," so to speak. ${ }^{9}$

To ensure that all coders used criteria that were consistent and accurate according to the methodological literature, we devised definitional requirements discussed in the next section. After coding the constructs for these papers, we calculated Fleiss' Kappa ${ }^{10}$ which indicated an inter-rater reliability of 0.76 . Given the high level of agreement between the coders, we concluded that the coding of the articles was reliable.

Table 2 summarizes the findings of this review. We identified a remarkably similar degree of misspecification in the IS literature to that of Jarvis et al. (2003) in the marketing literature. Jarvis et al. found a misspecification level of 29 percent whereas we found a 30 percent level (highlighted in the table). Given the demonstrated problem of measurement model misspecification in the IS field, we believe strongly that the field needs an approach for specifying formative constructs.

\section{How to Specify Formative Constructs}

The designation of a construct as formative or reflective is somewhat elusive in many fields, including IS. Furthermore, as determined in our examination of the literature, many constructs that we use in IS are not purely reflective and not purely formative and tend to be modeled simply as reflective constructs. Given the problems that occur when a construct is mismodeled, we need to do a better job in IS at specifying constructs. Even if a researcher is using measures previously validated and used in other research studies, the relationship between the measures and construct should still be closely examined to determine if the construct is reflective, formative,

\footnotetext{
${ }^{9}$ The heuristics we used to categorize the constructs were the following: If $0 \%$ to $33 \%$ of the items were incorrectly specified, the construct was classified as "correctly specified." If $67 \%$ to $100 \%$ of the items are incorrectly specified, the construct was classified as "misspecified." If $34 \%$ to $66 \%$ of the items split between formative and reflective, the construct was classified as "mixed." If the determination of a construct was ambiguous, we used the authors' classification.

${ }^{10}$ Fleiss' Kappa is similar in interpretation and calculation to Cohen's Kappa. While Cohen's Kappa assumes only two coders, Fleiss' Kappa allows for a computation of inter-rater reliability for $k$ coders.
} 


Table 2. Results of Coding of IS Literature Model Misspecification
\begin{tabular}{|l|c|c|c|c|}
\hline & \multicolumn{4}{|c|}{ Overall } \\
\hline & $\begin{array}{c}\text { Should be } \\
\text { Reflective }\end{array}$ & $\begin{array}{c}\text { Should be } \\
\text { Formative }\end{array}$ & Mixed & Total \\
\hline Modeled as Reflective & $180^{*}$ & $\mathbf{9 5}$ & 34 & 309 \\
& $(57 \%)$ & $(\mathbf{3 0} \%)$ & $(11 \%)$ & $(98 \%)$ \\
\hline Modeled as Formative & 0 & 7 & 0 & 7 \\
& $(0 \%)$ & $(2 \%)$ & $(0 \%)$ & $(2 \%)$ \\
\hline & 80 & 102 & 34 & 307 \\
& $(57 \%)$ & $(32 \%)$ & $(11 \%)$ & $(100 \%)$ \\
\hline
\end{tabular}

${ }^{*}$ Cell values represent number of constructs reported in articles assessed.

or mixed. This section discusses how to identify constructs as either formative, reflective, or mixed; provides a listing of properly specified formative and reflective constructs as an exemplar on how to identify the nature of a construct; and explains how to ensure that the entire domain of a formative construct is captured once it is specified (i.e., content validity).

\section{Identifying Formative Constructs}

Jarvis et al. (2003) state four primary decision rules for determining whether a construct is reflective or formative. Prior to data collection, researchers should apply these decision rules conceptually as they specify the constructs within the research model.

First, the researchers should consider the theoretical direction of causality between each construct and its measures. If the direction of causality is from the construct to the items, the construct is reflective. If causality is directed from the items to the construct, the construct is formative. To verify this decision rule, Jarvis et al. ask the researcher to consider the nature of the measures. First, do the items define the construct or are they manifestations of the construct? Items that define the construct are formative, while items that manifest the construct are reflective. Second, how do changes occur in the construct? With reflective constructs, changes in the measures do not cause changes in the construct, but rather changes in the construct cause changes in the indicators. Formative constructs work in the opposite manner. Changes in the measures do cause changes in the construct, but changes in the construct do not cause changes in the measures.

In applying this decision rule, consider the construct operational excellence as measured by Rai et al. (2006) using the following measures: product delivery cycle time, timeliness of after-sales service, and productivity improvements in terms of assets, operating costs, and labor costs. ${ }^{11}$ This example illustrates a situation in which the items define how the researcher interprets the concept of operational excellence. If one or more item improves, such as productivity, then operational excellence has improved. Let us contrast this with measures of operational excellence that are designed to be reflective. For example, items for a reflective version of the construct could be "the system has a positive impact on the organization's operations," "the system has improved the organization's operational performance," and "the system has significantly affected the organization's operations in a positive manner" (adapted from Gattiker and Goodhue 2005). In this latter reflective example, the measures are one representation of the operational excellence construct where a change in the construct itself is reflected by a change in the measures rather than the measures causing the change in the construct.

The second criteria, or decision rule, to determine if a construct is formative or reflective is to examine the interchangeability of the measures. Measures that are interchangeable and have a common theme are typically reflective. Good reflective measures, by definition, should be unidimensional and reflect this common theme. Formative measures may not be interchangeable and will often employ different themes. Furthermore, with formative measures, dropping one of the measures would affect the meaning of the construct since the construct is defined by these measures.

We can illustrate this decision rule using operational excellence again as the example. In the reflective representation of

\footnotetext{
${ }^{11}$ In their study, Rai et al. (2006) actually measured operational excellence as a subconstruct of the multidimensional construct named firm performance. However, the subconstructs that made up the multidimensional construct also have a formative relationship with the measures.
} 
the construct, the three measures are interchangeable and all represent the information system's impact on the organization's operations. All measures share this theme and we can easily drop one of the measures and still capture the essence of the concept. However, looking at the formative version of this construct, we can see that there are three different aspects being measured. Organizational productivity, delivery cycle time, and timeliness of after-sales service are very different representations of operational excellence. Removing one of these items changes how the researcher understands and interprets operational excellence.

Jarvis et al.'s third decision rule moves from the theoretical realm to the statistical realm and asks whether the measures covary with one another. Measures for reflective constructs are required to covary with one another. Internal consistency or reliability is important in reflective measures, meaning that all of the items are measuring the same phenomenon and if the value for one of the measures changes, then all of the other values should move in the same direction. With formative constructs, though, measures do not need to covary. In fact, formative measures should not have strong correlations with one another because this suggests multicollinearity. While multicollinearity is desirable for reflective measures, excessive multicollinearity in formative measures can destabilize the construct. The correlation among measures can be determined after data is collected, but the researcher could conceptually reason if the items within the construct should covary.

The items comprising the formative representation of operational excellence may covary, but would not necessarily need to covary. For example, productivity improvements (in terms of assets, operating costs, and labor costs) may or may not covary with timeliness of after-sales service. One could argue that to improve the timeliness of service, one has to increase labor costs. This would mean that it would be possible for timeliness of service to improve while productivity improvements decline. It could also be true that timeliness of service may improve without any additional cost expenditures (i.e., reflected in productivity improvements) if the processes and/or incentives for after-sales service changes. It is logical and reasonable for these measures to not covary, and the lack of covariation would not be surprising.

On the other hand, looking at the reflective operationalization of the construct, these items are all very similar and tap into the same concept of operational excellence. Therefore, the quintessential ideas of these measures - impact, operational performance, and affect-are expected to covary. If these measures did not covary, it would seem to imply that something was wrong with our measurement (unlike our formative construct example).
The final decision rule to identify formative constructs asks if the measures of the construct have the same antecedents and consequences. Formative constructs are composites or indices that are made up of measures that may be very different; thus, it is not necessary for the measures to have the same antecedents and consequences. Reflective measures, however, are interchangeable, and therefore have the same antecedents and consequences because the measures are manifestations of the construct. This last decision rule may appear confusing given that we are more accustomed to defining antecedents and consequences at the construct level. However, when you consider that a formative construct is made up of distinct items that form the construct, each item may, in fact, have very different antecedents and/or consequences.

For example, with operational excellence, the reasons (or antecedents) for an organization's high productivity may be different from the reasons for an organization's improved delivery cycle time and better after-sales service. These items may share some of the antecedents and/or consequences, but it is not required. The assumption, however, for the reflective operationalization of operational excellence is that the same factor caused a change in the construct, which is then reflected in each of the measures.

The decision rules explained here and used in our examination of the IS literature are summarized in Table 3, taken from Jarvis et al. ${ }^{12}$

While these decision rules provide guidance on how to identify a reflective or formative construct, we found that, in practice, many constructs are actually mixed. This means that a construct has some items and properties consistent with formative constructs while some items are consistent with reflective constructs.

An example of one such mixed construct is perceived usefulness (Davis 1989). Reflective measures typically pose statements that are supposed to direct respondents' attention repeatedly to the same concept. The original Davis statements displayed below should simply be rewordings of the core of the construct of usefulness.

\footnotetext{
${ }^{12}$ These decision rules for determining whether a construct is formative or reflective could be assessed a priori or through post hoc statistical analysis. Ideally, one would examine each construct's measures a priori using these decision rules based on the underlying theory base of the construct. These decision rules could then be applied in post hoc statistical analysis to confirm the $a$ priori assertions. The underlying difference between formative and reflective indicators should be based on conceptual/theoretical grounds before gathering any observations. Researchers should therefore prefer this conceptual grounding, all things being equal.
} 
Table 3. Decision Rules to Identify Construct as Formative or Reflective (Table 1 from "A Critical Review of Construct Indicators and Measurement Model Misspecification in Marketing and Consumer Research," C. B. Jarvis, S. B. MacKenzie, and P. M. Podsakoff, Journal of Consumer Research (30), September 2003, p. 203. Copyright $\odot$ 2003, University of Chicago Press. Used with permission.)

\begin{tabular}{|c|c|c|}
\hline Decision Rule & Formative Model & Reflective Model \\
\hline $\begin{array}{l}\text { 1. Direction of causality from construct to } \\
\text { measure implied by the conceptual } \\
\text { definition }\end{array}$ & $\begin{array}{l}\text { Direction of causality is from items to } \\
\text { construct }\end{array}$ & $\begin{array}{l}\text { Direction of causality is from } \\
\text { construct to items }\end{array}$ \\
\hline $\begin{array}{l}\text { Are the indicators (items) (a) defining } \\
\text { characteristics or (b) manifestations of } \\
\text { the construct? }\end{array}$ & $\begin{array}{l}\text { Indicators are defining characteristics } \\
\text { of the construct }\end{array}$ & $\begin{array}{l}\text { Indicators are manifestations of the } \\
\text { construct }\end{array}$ \\
\hline $\begin{array}{l}\text { Would changes in the indicators/items } \\
\text { cause changes in the construct or not? }\end{array}$ & $\begin{array}{l}\text { Changes in the indicators should } \\
\text { cause changes in the construct }\end{array}$ & $\begin{array}{l}\text { Changes in the indicator should not } \\
\text { cause changes in the construct }\end{array}$ \\
\hline $\begin{array}{l}\text { Would changes in the construct cause } \\
\text { changes in the indicators? }\end{array}$ & $\begin{array}{l}\text { Changes in the construct do not } \\
\text { cause changes in the indicators }\end{array}$ & $\begin{array}{l}\text { Changes in the construct do cause } \\
\text { changes in the indicators }\end{array}$ \\
\hline 2. Interchangeability of the indicators/items & $\begin{array}{l}\text { Indicators need not be } \\
\text { interchangeable }\end{array}$ & $\begin{array}{l}\text { Indicators should be } \\
\text { interchangeable }\end{array}$ \\
\hline $\begin{array}{l}\text { Should the indicators have the same or } \\
\text { similar content? Do the indicators } \\
\text { share a common theme? }\end{array}$ & $\begin{array}{l}\text { Indicators need not have the same or } \\
\text { similar content/indicators need not } \\
\text { share a common theme }\end{array}$ & $\begin{array}{l}\text { Indicators should have the same or } \\
\text { similar content/indicators should } \\
\text { share a common theme }\end{array}$ \\
\hline $\begin{array}{l}\text { Would dropping one of the indicators } \\
\text { alter the conceptual domain of the } \\
\text { construct? }\end{array}$ & $\begin{array}{l}\text { Dropping an indicator may alter the } \\
\text { conceptual domain of the construct }\end{array}$ & $\begin{array}{l}\text { Dropping an indicator should not } \\
\text { alter the conceptual domain of the } \\
\text { construct }\end{array}$ \\
\hline 3. Covariation among the indicators & $\begin{array}{l}\text { Not necessary for indicators to covary } \\
\text { with each other }\end{array}$ & $\begin{array}{l}\text { Indicators are expected to covary } \\
\text { with each other }\end{array}$ \\
\hline $\begin{array}{l}\text { Should a change in one of the } \\
\text { indicators be associated with changes } \\
\text { in the other indicators? }\end{array}$ & Not necessarily & Yes \\
\hline $\begin{array}{l}\text { 4. Nomological net of the construct } \\
\text { indicators }\end{array}$ & $\begin{array}{l}\text { Nomological net for the indicators } \\
\text { may differ }\end{array}$ & $\begin{array}{l}\text { Nomological net for the indicators } \\
\text { should not differ }\end{array}$ \\
\hline $\begin{array}{l}\text { Are the indicators/items expected to } \\
\text { have the same antecedents and } \\
\text { consequences? }\end{array}$ & $\begin{array}{l}\text { Indicators are not required to have } \\
\text { the same antecedents and } \\
\text { consequences }\end{array}$ & $\begin{array}{l}\text { Indicators are required to have the } \\
\text { same antecedents and } \\
\text { consequences }\end{array}$ \\
\hline
\end{tabular}

Item \#1: Using CHART-MASTER in my job would enable me to accomplish tasks more quickly.

Item \#2: Using CHART-MASTER would improve my job performance.

Item \#3: Using CHART-MASTER in my job would increase my productivity.

Item \#4: Using CHART-MASTER would enhance my effectiveness on the job.

Item \#5: Using CHART-MASTER would make it easier to do my job.

Item \#6: I would find CHART-MASTER useful in my job.

Although most researchers have assumed that this variable is reflective, one could legitimately question this. Accom- plishing tasks quickly (i.e., efficiently; Item \#1) may be quite distinct from accomplishing task effectively (Item \#4). There may also be an important distinction between job outcomes (Items \#2, 3, and 4) and job processes (Items \#1 and 5). If respondents somehow focused on these differences, the measures could be corrupted. While this example of perceived usefulness does not fully meet the definition of formative, neither does it fully meet the definition of reflective.

In the literature, most researchers assume these items for perceived usefulness to be close substitutes, intended to tap into the same quintessential core of the construct. They assume that removing any one of them from the scale will not affect the findings. A reason for this misconception is due to 
the high Cronbach's alpha levels for this construct, some of which are incredulous (Straub et al. 2004). This is a dangerous interpretation, however, in that it reasons backward from statistics to content rather than forward from theory to content. One viable explanation for high reliabilities for this particular operationalization of the construct, for instance, is the blocking of items and the likelihood of huge common methods bias in the typical administration of this instrument (Straub et al. 2004; Straub and Burton-Jones 2007).

It is possible, however, to measure perceived usefulness using only reflective items. For example, van der Heijden (2004) uses the perceived usefulness construct to examine hedonic information systems using the following items:

Item \#1: I can decide more quickly and more easily which movie I want to go see

Item \#2: I can better decide which movie I want to go see than in the past

Item \#3: I am better informed about new movies

Item \#4: I can decide more quickly and more easily whether I want to go see a particular movie or not

Item \#5: I can better decide whether I want to go see a particular movie or not

In this example, all five items are examining the same ideas within the perceived usefulness construct. Therefore, one cannot assume that all operationalizations of perceived usefulness are formative or reflective. The researcher must examine the relationship between each item and the construct to determine if the overall construct is formative or reflective.

If a researcher is considering using a construct that seems to have some items that are reflective, while others are formative, there are approaches to address this issue $a$ priori to data collection. First, the researcher could model the construct as having both formative and reflective items. This is actually an ideal approach to ensure statistical identification of a structural model with formative constructs when using covariance-based SEM (we discuss this more later in this paper). Second, if the reflective items are measuring exactly the same facet of the construct, and the content validity of the construct would not be affected, all of the reflective items except one could be removed from the measure. The result would be a construct that has the same content validity (if the correlated items are interchangeable) as the original construct, and the researcher would be left with a purely formative construct. Finally, if the construct is important and a primary focus of the study, it may be most appropriate to model the construct as multidimensional. One could have separate dimensions for each aspect of the construct. This final option may increase the complexity of the model, but it may better describe the construct, measures, and underlying theory.
Tables 4, 5, and 6 provide examples of properly specified formative, multidimensional, and reflective constructs within the IS literature. These examples satisfy the decision rules discussed in this section and summarized in Table 3. This list is by no means exhaustive, but it does provide some exemplars of properly specified constructs across a variety of topic areas to provide some examples of each type of construct. Appendix B provides a much larger listing of properly specified constructs identified in our analysis of the IS literature in MIS Quarterly and Information Systems Research in 20032005.

\section{Ensuring Content Validity for Formative Constructs}

Content validity assesses whether the researcher has chosen measures that appropriately capture the full domain of the construct (Straub et al. 2004). When specifying a construct that is either formative or reflective, it is critical that the entire domain of the construct is captured. Constructs are the basic elements of a theory and the nature of these units is critical to effective theory development. Dubin's (1976) seminal work on theory building presents a set of guidelines on how to draw theoretical constructs from real-world phenomenon and the issues for developing a theoretical model:

1. Units (by theoretical units, Dubin means what we are referring to as constructs)

2. Laws of interaction of the units

3. Boundaries within which the theory is expected to hold

4. System states in each of which the units interact differently

5. Propositions of the theory

6. Empirical indicators of the terms of the propositions (in order to test the validity of the model in the real world)

7. A testable hypothesis

Because of its basis in theory in Dubin's issues 1 and 6, content validity should be assessed as the construct is being specified and prior to data collection. This will ensure that the selected indicators accurately represent constructs (Nunnally 1978). One must decide at the theoretical level if the construct should be measured reflectively or formatively, as this decision dramatically alters the specific items used to measure the construct (Diamantopoulos and Siguaw 2006).

Given that formative constructs are defined by the dimensions or measures that form them, it is absolutely imperative to establish content validity. Without a full and complete definition of a formative construct, important aspects can be left out, and this will result in a misspecification of the construct. 


\section{Table 4. Examples of Properly Specified Formative Constructs in the IS Literature}

\begin{tabular}{|c|c|}
\hline Construct Name (Study) & Indicators Used to Measure Construct \\
\hline Perceived User Resources (Mathieson et al. 2001) & $\begin{array}{l}\text { Specific resources needed to use a software package: } \\
\text { Access to hardware and software } \\
\text { Necessary knowledge } \\
\text { Time } \\
\text { Financial resources } \\
\text { Available assistance } \\
\text { Documentation } \\
\text { Access to data }\end{array}$ \\
\hline Project Champion (Wixom and Watson 2001) & $\begin{array}{l}\text { Champion for project is from: } \\
\text { IS } \\
\text { Functional area }\end{array}$ \\
\hline Team Skills (Wixom and Watson 2001) & $\begin{array}{l}\text { Team members had: } \\
\text { Technical skills } \\
\text { Interpersonal skills }\end{array}$ \\
\hline User Participation (Wixom and Watson 2001) & $\begin{array}{l}\text { Users worked with IS on project } \\
\text { Users assigned full time to project } \\
\text { Users performed activities related to project }\end{array}$ \\
\hline Declarative Knowledge (Yi and Davis 2003) & $\begin{array}{l}\text { Ability to understand tasks in Excel, such as: } \\
\text { Copying formulas } \\
\text { Copy contents of cells } \\
\text { Use menu shortcuts } \\
\text { Using operators }\end{array}$ \\
\hline Task Performance (Yi and Davis 2003)) & $\begin{array}{l}\text { Ability to perform tasks in Excel, such as: } \\
\text { Compute profits } \\
\text { Compute sales, expenses } \\
\text { Compute average amounts of profits, sales, and expenses } \\
\text { Compute year-to-date profits } \\
\text { Calculate change in sales }\end{array}$ \\
\hline $\begin{array}{l}\text { Perceived Effectiveness of Institutional Structures } \\
\text { (Pavlou and Gefen 2005) }\end{array}$ & $\begin{array}{l}\text { Confidence and effectiveness of feedback technologies } \\
\text { Trust and protection of escrow services } \\
\text { Protection and confidence in credit card guarantees } \\
\text { Trust in Intermediary }\end{array}$ \\
\hline Sellers' Performance (Pavlou and Gefen 2005) & $\begin{array}{l}\text { Competitive pricing } \\
\text { Timeliness of product delivery } \\
\text { High quality products }\end{array}$ \\
\hline $\begin{array}{l}\text { Sources of Psychological Contract Violation with } \\
\text { Individual Seller (Pavlou and Gefen 2005) }\end{array}$ & $\begin{array}{l}\text { Fraud } \\
\text { Product misrepresentation } \\
\text { Contract default } \\
\text { Delivery delay } \\
\text { Failure to acknowledge product guarantees } \\
\text { Refusal to comply with payment policy }\end{array}$ \\
\hline
\end{tabular}




\section{Table 5. Examples of Properly Specified Multidimensional Constructs in the IS Literature}

\begin{tabular}{|c|c|c|}
\hline $\begin{array}{l}\text { Construct Name - Type of } \\
\text { Construct(study) }\end{array}$ & $\begin{array}{l}\text { Sub-construct Name (Type of } \\
\text { Construct) }\end{array}$ & $\begin{array}{c}\text { Examples of Indicators Used to Measure } \\
\text { Construct }\end{array}$ \\
\hline \multirow{4}{*}{$\begin{array}{l}\text { Observational Learning } \\
\text { Processes - Formative } \\
\text { (Yi and Davis 2003) }\end{array}$} & Attention (Reflective) & $\begin{array}{l}\text { Paid close attention } \\
\text { Able to concentrate } \\
\text { Held my attention } \\
\text { Was absorbed }\end{array}$ \\
\hline & Retention (Reflective) & $\begin{array}{l}\text { Summarize the key aspects } \\
\text { Symbolically process } \\
\text { Mentally visualize } \\
\text { Mentally practice }\end{array}$ \\
\hline & Production (Reflective) & $\begin{array}{l}\text { Accurately reproduce } \\
\text { Enough practice } \\
\text { Produce the procedural steps } \\
\text { Helped me practice }\end{array}$ \\
\hline & Motivation (Reflective) & $\begin{array}{l}\text { Motivated me } \\
\text { Helped me see usefulness } \\
\text { Increased my intention } \\
\text { Showed me the value }\end{array}$ \\
\hline \multirow{3}{*}{$\begin{array}{l}\text { Trustworthiness - Formative } \\
\text { (Serva et al. 2005) }\end{array}$} & Integrity (Reflective) & $\begin{array}{l}\text { Truthful } \\
\text { Honest } \\
\text { Keeps commitments } \\
\text { Sincere and genuine }\end{array}$ \\
\hline & Benevolence (Reflective) & $\begin{array}{l}\text { Acts in my best interests } \\
\text { Does its best to help me } \\
\text { Concerned about my well-being }\end{array}$ \\
\hline & Ability (Reflective) & $\begin{array}{l}\text { Competent and effective } \\
\text { Performs role well } \\
\text { Capable and proficient } \\
\text { Knowledgeable }\end{array}$ \\
\hline \multirow{3}{*}{$\begin{array}{l}\text { Firm Performance - Formative } \\
\text { (Rai et al. 2006) }\end{array}$} & $\begin{array}{l}\text { Operational Excellence } \\
\text { (Formative) }\end{array}$ & $\begin{array}{l}\text { Product delivery cycle time } \\
\text { Timeliness of after sales service } \\
\text { Productivity improvements }\end{array}$ \\
\hline & $\begin{array}{l}\text { Customer Relationship } \\
\text { (Formative) }\end{array}$ & $\begin{array}{l}\text { Strong and continuous bond with customers } \\
\text { Knowledge of buying patterns of customers }\end{array}$ \\
\hline & Revenue Growth (Formative) & $\begin{array}{l}\text { Increasing sales of existing products } \\
\text { Finding new revenue streams }\end{array}$ \\
\hline
\end{tabular}




\begin{tabular}{|c|c|}
\hline Construct Name (Study) & Indicators Used to Measure Construct \\
\hline Perceived User Resources (Mathieson et al. 2001) & $\begin{array}{l}\text { Have resources, opportunities and knowledge to use system } \\
\text { No barriers to using system } \\
\text { Would be able to use system if I wanted to } \\
\text { Have access to resources I need to use system }\end{array}$ \\
\hline $\begin{array}{l}\text { Ease of Use (Brown and Venkatesh 2005; Gefen et } \\
\text { al. 2003; Karimi et al. 2004; Lewis et al. 2003; van } \\
\text { der Heijden 2004; Wixom and Todd 2005) }\end{array}$ & $\begin{array}{l}\text { Interaction with software is clear and understandable } \\
\text { Easy to get software to do what I want it to do } \\
\text { Easy to use software } \\
\text { Learning to use software is easy for me }\end{array}$ \\
\hline Role Overload (Ho et al. 2003) & $\begin{array}{l}\text { Need to reduce parts of my role } \\
\text { I feel overburdened in my role } \\
\text { I have been given too much responsibility } \\
\text { My work load is too heavy } \\
\text { Amount of work given interferes with quality }\end{array}$ \\
\hline Source Credibility (Sussman and Siegal 2003) & $\begin{array}{l}\text { Person writing message is knowledgeable } \\
\text { Person is an expert on message topic }\end{array}$ \\
\hline Team Cohesion (Jarvenpaa et al. 2004) & $\begin{array}{l}\text { I feel part of a team } \\
\text { My team works together } \\
\text { My team helps one another } \\
\text { My team gets along better }\end{array}$ \\
\hline Task Efficiency (Gattiker and Goodhue 2005) & $\begin{array}{l}\text { Employees need less time since system has been implemented } \\
\text { The system saves time } \\
\text { System is less time-consuming } \\
\text { System helps employees be more productive }\end{array}$ \\
\hline Client Learning (Majchrzak et al. 2005) & $\begin{array}{l}\text { Dialogue reoriented thinking } \\
\text { Dialogue questioned preconceptions } \\
\text { Dialogue expanded scope of thinking }\end{array}$ \\
\hline Trust Propensity (Pavlou and Gefen 2005) & $\begin{array}{l}\text { Trust sellers unless I have a reason not to } \\
\text { Give sellers benefit of the doubt } \\
\text { Trust sellers until they prove otherwise }\end{array}$ \\
\hline Reputation (Wasko and Faraj 2005) & $\begin{array}{l}\text { I earn respect by participating } \\
\text { I feel that participation improves my status in the profession } \\
\text { I participate to improve my reputation }\end{array}$ \\
\hline
\end{tabular}

While content validity of reflective measures does not have such a powerful downstream influence on instrument validation (Straub et al. 2004), content validity does for formative constructs and so should be a mandatory practice for researchers using formative constructs.

To establish content validity, a common method is via a literature review to scope the domain of the construct. Beyond a literature review, other methods to ensure content validity include expert panels and Q-sorting (Boudreau et al. 2001). (As noted below, Q-sorting can also help to determine construct validity.) A two-step Q-sort may be one of the best methods to assess content validity for formative constructs. The first round of Q-sorting asks a person (with no prior knowledge of the study) to examine a series of cards containing the measures that will be used for each of the constructs and to place each card into one of several categories (comprised of the formative and reflective constructs). If the measures and constructs theoretically identified by the researcher sufficiently match the results of the Q-sort, one can say that content (and construct validity) has been achieved. For an additional test of robustness, a second round of Qsorting can occur, but in this round, the person does not receive a listing of categories. In this round, the person must 
define their own categories. This procedure can be useful in determining (1) if all of the facets of the construct are measured (i.e., content validity) and (2) if the measures for each construct belong together (i.e., convergent validity) and are distinguishable from measures of other constructs (i.e., discriminant validity). For an extensive description of the procedures of Q-sorting applied in an IS research context, see Moore and Benbasat (1991) and for an example of the two step Q-sort described above, see Storey et al. (2000). Of course, Q-sorting cannot detect underspecification of a formative construct, which should be safeguarded through a careful evaluation of facets specified against those suggested by the informing theory base for the construct.

\section{What Next After Specifying Formative Constructs?}

Once a researcher identifies one or more constructs in the model as formative, the research model must now be considered formative. The presence of even one formative construct impacts choices for follow-up statistical analysis, including how to validate formative constructs within the model. Unfortunately, formative constructs have a poor reputation due to researchers using the term formative as an excuse for avoiding validity testing. If reliability is poor or if the construct does not load cleanly on a factor analysis, the researcher may declare the construct to be formative (Bollen and Lennox 1991). Sadly, lack of guidelines for validating and analyzing formative constructs may have allowed some researchers to circumvent the standard procedures for validating a construct. Reflective constructs have clear guidelines for validation (Straub et al. 2004), but formative constructs are constrained to using the "best available" approaches discussed within the literature for validation and analysis. Given the lack of attention to formative constructs in the literature, there is still some ambiguity to this process. We hope to synthesize and clarify the current literature on this discussion here.

\section{Prior to Data Collection}

Before data collection, the researcher should anticipate her/his data analysis. If the researcher wants to use covariance-based SEM, it is critical to determine a priori to data collection if the model is identified. Identification is necessary because it implies that there is a solution for each parameter within the model; a model that is underidentified will produce inconsistent parameter estimates and uninterpretable fit statistics (Rigdon 1995). Identification must be considered with reflec- tive models, but the problem is often even more complicated for formative models.

Formative constructs in isolation are statistically underidentified because of "indeterminacies associated with the scale of measurement for the latent construct and the construct level error term" (Jarvis et al. 2003, p. 213). To achieve identification (and thus obtain a solution to the model), a formative construct must be placed within a larger model (Diamantopoulos and Winklhofer 2001). However, even in a larger model, it becomes difficult to identify all parameters.

There are, however, several alternative solutions to ensure a formative model is identified (see Table 7), some of which we do not advocate. The first is to alter your model to fit the statistical tool. If structural model identification is not considered prior to data collection, the only possible solution to analyze the model using covariance-based SEM, for instance, is to remove structural paths, constrain construct error terms to zero, or modify the entire model structure (MacCallum and Browne 1993). Making these modifications to force formative models to work within the confines of covariance-based SEM affects the theoretical implications and the interpretation of the model. By constraining arbitrary paths, we essentially begin to force a square peg (i.e., the theoretical model) into a round hole (i.e., covariance-based SEM tools).

Another method to achieve identification that we do not recommend is to alter the measurement model by modeling formative constructs as reflective (MacCallum and Browne 1993). As shown earlier in this paper, this only masks the problem and can give rise to Type I and Type II errors. To avoid the problem of identification completely, a researcher can use components-based SEM (e.g. PLS) to model formative nomologies (Chin 1998a). Please note that if, in spite of the issues raised in this section, a researcher still prefers covariance-based SEM, it is still possible to carry this forward. Identification of formative models can be achieved, but the structural model should be fully examined to ensure identification in the theory building stage prior to data collection.

\section{After Data Collection}

Once both the measurement and structural model has been specified according to theory and the given research questions, the researcher may then begin to collect data. After data collection, researchers then usually begin to evaluate construct validity and reliability for reflective constructs. However, these two forms of validity should not be conducted in the same manner for formative measures, given the differences between reflective and formative constructs. 
Construct validity is typically assessed by both convergent validity, which detects if the measures for a construct are more correlated with one another than with measures of another construct, and discriminant validity, which determines if the measures are isolated as distinct constructs. Because the correlations among indicators within a construct do not need to be higher than correlations between indicators of different constructs (MacCallum and Browne 1993), common factor analysis is useless for formative constructs, because there is no requirement that the measures of the construct be highly correlated (Rossiter 2002). Additionally, with formative constructs, there is no restriction on the magnitude of correlations between indicators, so there are no definitive rules on between- versus within-construct correlations (Bollen and Lennox 1991). Therefore, methods of determining construct validity with reflective constructs that focus on common variance do not apply well to formative constructs.

Given the objective of formative constructs is to retain the unique variance of each measure and not just the shared variance among measures, principal component analysis, and not common factor analysis, should be applied to evaluate the reduced dimensionality of the measures (Chin 1995). ${ }^{13}$ To extract the principal components, unities are specified along the diagonals of the correlation matrix rather than communalities, which are used for common factor analysis (Hair et al. 1987). This specification of unities along the diagonal of the correlation matrix brings the full variance-(1) variance that is common across measures, (2) variance that is specific to a measure, and (3) error variance - into the principal component analysis. As a result, hybrid factors can be extracted that contain common variance and unique variance. Unlike common factor analysis, where one examines the loadings, in principal components analysis for formative constructs, the weights must be examined.

Diamontopolous and Winklhofer (2001) suggest that if any of the item weightings for formative measures are nonsignificant, it may be appropriate to remove nonsignificant indicators (one at a time) until all paths are significant and a good fit is obtained. When removing measures, however, it is important to ensure that the construct is still measuring the entire domain and content validity is preserved. Because of this, some researchers suggest retaining nonsignificant indicators to retain content validity (Bollen and Lennox 1991). Furthermore, if several indicators that are nonsignificant are coupled with a small error term for the formative construct, it is likely that multicollinearity is the culprit (Diamantopoulos 2006).

\footnotetext{
${ }^{13}$ As the unique variance of measures approaches zero, the factor matrix and the factor correlations using principal components or common factor analysis approach identity.
}

Unlike reflective indicators, where multicollinearity between construct items is desirable (illustrated by high Cronbach's alpha or internal consistency scores), excessive multicollinearity in formative constructs can destabilize the model. Reliability in the form of very high internal consistency of indicators is actually undesirable for formative constructs. If measures are highly correlated, it may suggest that multiple indicators are tapping into the same aspect of the construct. To ensure that multicollinearity is not present, one can use the VIF (variance inflation factor) statistic to determine when one's formative measures are too highly correlated. Traditionally, general statistics theory suggests that multicollinearity is a concern if the VIF is higher than 10; however, with formative measures, multicollinearity poses more of a problem. If the VIF statistic for formative measures is greater than 3.3 (Diamantopoulos and Siguaw 2006), the researcher should address the issue by using one of the approaches outlined in Step 2.1 in Table 7.

Another viable option to test for reliability is test-retest item reliability if the items are expected to remain stable over time. Unlike internal consistency tests of reliability where collinearity would pose a problem for formative constructs, another test of reliability that would not suffer from the collinearity issue is consistency of measures over time (Trochim 2000). With this option, the measures of a construct are gathered at two different points in time. The correlations between the same measures over time could provide a reasonable basis for assessing reliability. Test-retest is typically performed at the construct level; however, because formative measures are capturing different dimensions and perspectives of a construct, it seems more appropriate to compare these item-by-item over time. This would provide an indication of the robustness of the individual items that form the construct.

Diamantopoulos (2006) also recommends examining the error term in formative constructs to glean insights into the measurement of the construct. If the error term is large, the researcher should see if the entire content of the construct under study was appropriately captured. Even if all of the indicators are significantly related to the construct, but the error term is large, there is the potential that some aspects of the construct are not adequately captured. If many indicators are not significant and the error term is large, the researcher should either redefine the construct or develop a better set of items to capture its facets. Diamantopolous suggests the following guidelines for examining error term values based on Cohen's (1988) guidelines for multiple regression: $f^{2}$ values of $0.02\left(\mathrm{R}^{2}=0.0196\right), 0.15\left(\mathrm{R}^{2}=0.13\right)$, and $0.35\left(\mathrm{R}^{2}=0.26\right)$ refer to a small, moderate, and large effect size, respectively.

After validating the formative measurement model, a researcher must analyze the structural model. Structural equa- 


\section{Table 7. Summary of Literature Related to Assessing and Analyzing Formative Constructs}

Phase I: Prior to Data Collection

\section{Step 1.1: Identify Formative Constructs}

Using the following criteria, determine if you have formative constructs:

1) Do the indicators predict the construct? (Diamantopoulos and Winklhofer 2001; Jarvis et al. 2003)

2) Does dropping a measure change what the construct is measuring? (Diamantopoulos and Winklhofer 2001; Jarvis et al. 2003)

3) Does a change in one measure of the construct not require a change in all other measures of the construct? (Diamantopoulos and Winklhofer 2001; Jarvis et al. 2003)

4) Do the measures have different antecedents and consequences? (Diamantopoulos and Winklhofer 2001; Jarvis et al. 2003) If all of these criteria are true, then we are in the presence of a formative construct. If a majority of the criteria are true, then you should consider if the theory base typically views it as a formative construct.

Step 1.2: Validate Formative Constructs

\begin{tabular}{|c|c|c|}
\hline Asse & & $\begin{array}{l}\text { Evaluate if the set of indicators underspecify the domain of the construct based on explicated facets in th } \\
\text { theory base } \\
\text { Q-sorting or Expert Validation to evaluate if the measures can be categorized as per theoretical } \\
\text { predictions (Straub et al. 2004) }\end{array}$ \\
\hline \multicolumn{3}{|r|}{ Step 1.3: Assess Structural Model } \\
\hline $\begin{array}{l}\text { Model } \\
\text { (Jarvis } \\
\text { MacCa } \\
\text { 1993; } 1 \\
\text { 2005) }\end{array}$ & \multicolumn{2}{|r|}{$\begin{array}{l}\text { Assess if the structural model will have problems with identification (if using covariance-based SEM). If appr } \\
\text { priate, modify the model to prevent problems with identification by taking one or more of the following steps: } \\
\text { 1) Constrain one or more structural paths or construct error terms to zero } \\
\text { 2) Decompose the formative construct if it only emits a single path to a reflective construct (see Figure 3) } \\
\text { 3) Ensure the formative construct has at least two structural paths to reflective constructs } \\
\text { 4) Include two reflective measures as part of the formative construct } \\
\text { 5) Include one reflective measure as part of the formative construct and one structural path leading to a } \\
\text { reflective construct }\end{array}$} \\
\hline \multicolumn{3}{|r|}{ Phase II: After Data Collection } \\
\hline \multicolumn{3}{|r|}{ Step 2.1: Validate Formative Constructs } \\
\hline & \multicolumn{2}{|r|}{$\begin{array}{l}\text { Use principal components analysis (rather than common factor analysis) to examine the item weightings for } \\
\text { measures. } \\
\text { 1) May choose to eliminate nonsignificant items (Diamantopoulos and Winklhofer 2001) } \\
\text { 2) May choose to keep nonsignificant items to preserve content validity (Bollen and Lennox 1991) }\end{array}$} \\
\hline Eval & \multicolumn{2}{|r|}{$\begin{array}{l}\text { Examine multicollinearity to determine if VIF < } 3.3 \text { for formative constructs (Diamantopoulos and Siguaw 2006). } \\
\text { If multicollinearity exists, available options include: } \\
\text { 1) Model construct as having both formative and reflective measurement items } \\
\text { 2) Remove correlated items if content validity is not affected } \\
\text { 3) Collapse correlated items into a composite index } \\
\text { 4) Convert into a multidimensional construct } \\
\text { Test-Retest Item Reliability (if appropriate) }\end{array}$} \\
\hline \multicolumn{3}{|c|}{ Step 2.2 (Option A): Analyze Formative Constructs via Covariance-Based SEM (e.g., LISREL OR EQS) OR } \\
\hline $\begin{array}{l}\text { Evaluate } \\
\text { Specificat } \\
\text { al. 2003) }\end{array}$ & & $\begin{array}{l}\text { Analyze model with items within exogenous formative constructs co-varying with other items within the } \\
\text { formative construct and all other exogenous constructs } \\
\text { Analyze model with inter-item correlation among items within the formative construct, but no correlation } \\
\text { between formative items and other exogenous constructs } \\
\text { Analyze model with no inter-item correlation among items within the formative construct and no correlation } \\
\text { between formative items and other exogenous constructs } \\
\text { Perform chi-square difference test to determine which model to use }\end{array}$ \\
\hline \multicolumn{3}{|c|}{ Step 2.2 (Option B): Analyze Formative Constructs via Components-Based SEM (e.g., PLS) } \\
\hline & & $\begin{array}{l}\text { Specify formative constructs in the research model using Mode } B \text { (all formative constructs in model) or } \\
\text { Mode } C \text { (both formative and reflective constructs in model) } \\
\text { Examine model weights for formative measures and model loadings for reflective measures. } \\
\text { Assess } R^{2} \text { values for endogenous variables in structural model }\end{array}$ \\
\hline
\end{tabular}


tion modeling is a tool that can be used to analyze both the measurement and structural model at once. This notwithstanding, if a model contains formative constructs, some additional considerations are warranted.

In covariance-based SEM, the common practice is to allow exogenous constructs to freely correlate with one another. However, if there are exogenous formative constructs within the structural model, the question arises as to whether each of the individual items of the formative constructs will freely correlate with one another and all other exogenous constructs. Therefore, the researcher can examine three different alternatives (see our Step 2.2 Option A in Table 7) and use a chisquare difference test to determine which model has the best fit (Jarvis et al. 2003). This chi-square difference test will reveal which of the three structural models should be used for further analysis.

Components-based SEM (e.g., partial least squares or PLS), is a widely used alternative to covariance-based SEM in IS research. Like covariance-based SEM, this analysis approach allows one to examine both the measurement and structural model simultaneously. While covariance-based SEM focuses on achieving the best fit for the research model, componentsbased SEM aims to maximize the explained variance of endogenous variables (Gefen et al. 2000). Furthermore, components-based SEM is useful when a research model is posited in a domain where theory and/or data are weak (Wold 1985). A benefit of using components-based SEM with formative models is that statistical identification problems are not at issue (Chin 1998b). When interpreting the results of components-based SEM for a measurement model with formative constructs, the focus should be on the weights of each measure rather than the loadings (which are used to assess reflective constructs) (Chin 1998b). Overall evaluation of formative models is essentially the same as evaluating reflective models in components-based SEM. The $\mathrm{R}^{2}$ for each endogenous variable in the structural model should be examined in a manner similar to the procedures used in regression. Bootstrapping and jackknifing can be used to evaluate the accuracy and significance of the estimates for both the measurement and structural model (Gefen et al. 2000).

\section{Conclusion}

\section{Guidelines for Reviewers}

A primary contribution of this work is a discussion of how to specify formative constructs; however, some cautionary notes are appropriate. Therefore, we also provide a discussion specifically for journal reviewers regarding how to interpret our work. At best, reviewers will use this discussion reasonably to ensure authors properly specify research models and obtain the best results possible. At worst, this paper will become an obstacle for valuable research that uses formative constructs and/or structural equation modeling. Therefore, we would like to offer our own interpretation of how reviewers should apply our guidelines when evaluating a manuscript.

First, when evaluating a manuscript, reviewers should determine whether the constructs measured within a research study are formative or reflective in nature. Reviewers should be wary of research that assumes every construct is reflective without fully examining the relationship between items and constructs. Reviewers should closely examine constructs classified as formative or multidimensional. What we do not wish to see as a result of the current study is researchers claiming that poor reflective measures are formative in an attempt to avoid traditional tests for validity. Based on our sampling of the literature, we believe that there is not a problem currently with researchers misspecifying reflective constructs as formative, and would like to ensure that we do not unintentionally introduce this as an issue into the IS literature.

We would also like to encourage reviewers to ensure that suitable tests for validity are performed for formative constructs. Some published research using formative constructs contains reliability or construct validity tests that are unnecessary (or, worse still, misdirected), given the nature of formative constructs. The present research has tried to explain why traditional methods for assessing the construct validity and reliability for reflective constructs are not appropriate for formative constructs. Based on the extant methodological literature, we also present options to researchers seeking to validate formative constructs as part of their data analysis.

However, many tests for validity require additional testing and examination before they can be rigorously applied to every study that uses formative constructs. We would like to remind reviewers that all empirical validation methods, even those used for reflective methods, have some element of subjectivity (e.g., cutoff values for Cronbach's alpha or internal consistency). The empirical tests we suggest have elements of subjectivity, we hasten to note. These tests are offered not because they are perfected, but because they provide a means of focusing researchers' efforts when validating formative constructs. Our goal is not to hinder the field in developing new instruments and constructs, but rather to encourage researchers to be aware of the differences between and implications of using formative and reflective constructs. Importantly, reviewers should consider the context when reviewing a paper. Similar to how Cronbach's 
alpha or other reliability guidelines are more forgiving when a researcher is conducting exploratory work or developing new scales, the same holds true when validating formative constructs. For example, a paper describing the development of a new scale should not be rejected solely because the developer failed to identify and incorporate all relevant facets of a formative construct.

Likewise, we are not suggesting that covariance-based SEM not be used in the IS field when there are formative constructs in the research model. Structural equation modeling has become more prevalent within IS and this is a positive development for our field. Using covariance-based SEM for models with formative constructs is more complex than it is for structural models with only reflective constructs. Proper planning prior to data collection can make it feasible to use covariance-based SEM for formative models. Our motivation in discussing issues related to covariance-based and components-based SEM in this manuscript is to encourage researchers to consider modeling issues during the theory development stages, rather than after data collection. Reviewers should ensure that researchers are using the best statistical method for data analysis rather than choosing a method that is perceived as "easier" because the model has one or more formative constructs within the model.

\section{Limitations and Future Research}

Addressing the issue of formative versus reflective constructs, this paper has found that the IS field, like marketing, has problems in misspecification. Further analysis via simulation reveals that both Type I and Type II errors are prevalent when such misspecification occurs.

Nevertheless, the paper has limitations that should be dealt with in future research. First, we looked at the same models set forth in the Jarvis et al. (2003) marketing study, but more complex and simpler models can and should also be tested. We extended the work of Jarvis et al. by adding a nonsignificant path and testing additional sampling conditions, but there could be even more extensive variations in models, indicators, and paths to see what this tells us about the robustness of typical models in the presence of misspecification. More simulations to examine the boundary conditions are needed to develop and present guidelines to identify and validate formative constructs.

Second, some researchers may prefer to use regression and indices of measures, even though by this choice they are not modeling the measurement error as with SEM. The choice of modeling a construct as formative versus an index should be determined a priori by the researcher based on the choice of theory and prior research in this area. In fact, there are situations when researchers may need to use composite indexes rather than formative constructs. First, there can be theoretical reasons for a researcher to a priori determine the weights of indicators and to use composite indexes based on these weights. Second, a researcher may observe the formative indicators to be highly correlated in an empirical context and may explore the use of a composite index to address such multicollinearity. Finally, a researcher may use composite indexes in place of formative constructs to potentially address identification problems in covariance-based SEM. Of course, collapsing the formative indicators into a single measure using an index or summated scale changes the level of abstraction within the construct itself and may affect both the measurement and structural model. IS researchers can explore what would happen when weights are specified $a$ priori, for instance from theory, to determine composite indexes as opposed to being calculated from empirical observations to determine formative constructs. Such findings could be both interesting and perhaps even controversial.

Third, given that IS researchers use both PLS and covariancebased SEM applications like LISREL, future research should investigate the implications of misspecification of the same model using these techniques. While we have begun the discussion in the current paper, this subject warrants detailed future investigation.

\section{Contributions}

With the wide availability of covariance-based SEM tools, it has become apparent that many researchers simply assume that constructs are, by default, reflective (Diamantopoulos and Winklhofer 2001). The misspecification of formative indicators as reflective has been previously documented in the fields of marketing (Jarvis et al. 2003) as well as, in a more limited study, information systems (Chin 1998a). With the current study, we report what we interpret to be convincing evidence that misspecification is a severe scholarly problem in the information systems field.

Because of the lack of understanding in specifying formative constructs, in many instances, formative constructs have been specified incorrectly as reflective even in publications that have appeared in premier scholarly journals. Furthermore, errors have also been committed on the other side as researchers have turned to formative models, not because they are theoretically justified, but to excuse poor construct validity or reliability scores (Bollen and Lennox 1991).

It is imperative that scholars specify these models based on theoretical considerations and then use empirical approaches 
to validate both reflective and formative measures. To assist researchers working with formative constructs, this work critically examines the literature, drawing from it the best thinking about these important methodological issues. It also assesses the likelihood of misspecifiying models as formative or reflective on statistical conclusion validities such as Type I and Type II errors. Our replication and extension of the study by Jarvis et al. shows that Type I and Type II errors can occur when constructs are misspecified. We also examine the prevalence of misspecification in the IS field and provide guidance and exemplars of how to properly specify constructs. In addition, we explain to researchers the action needed to assess and analyze formative constructs using a combination of the best available approaches in the literature.

\section{Acknowledgments}

We would like to thank the editors and anonymous reviewers for their insights. We believe that the review process greatly strengthened the paper.

\section{References}

Ahuja, M. K., and Thatcher, J. B. "Moving Beyond Intentions and Toward the Theory of Trying: Effects of Work Environment and Gender on Post-Adoption Information Technology Use," MIS Quarterly (29:3), September 2005, pp. 427-459.

Bandalos, D. L. "The Effect of Item Parceling on Goodness-of-Fit and Parameter Estimate Bias in Structural Modeling," Structural Equation Modeling (9:1), 2002, pp. 78-102.

Bandalos, D. L., and Finney, S. J. "Item Parceling Issues in Structural Equation Modeling," in New Developments and Techniques in Structural Equation Modeling, G. A. Marcoulides and R. E. Schumaker (eds.), Lawrence Erlbaum Associates, Hillsdale, NJ, 2001, pp. 362-427.

Bassellier, G., and Benbasat, I. "Business Competence of Information Technology Professionals: Conceptual Development and Influence on IT-Business Partnerships," MIS Quarterly (28:4), December 2004, pp. 673-694.

Bassellier, G., Benbasat, I., and Reich, B. H. "The Influence of Business Managers' IT Competence on Championing IT," Information Systems Research (14:4), December 2003, pp. 317-336.

Bhattacherjee, A., and Premkumar, G. "Understanding Changes in Belief and Attitude Toward Information Technology Usage: A Theoretical Model and Longitudinal Test," MIS Quarterly (28:2), June 2004, pp. 229-254.

Bock, G.-W., Zmud, R. W., Kim, Y.-G., and Lee, J.-N. "Behavioral Intention Formation in Knowledge Sharing: Examining the Roles of Extrinsic Motivators, Social-Psychological Forces, and Organizational Climate," MIS Quarterly (29:1), March 2005, pp. 87-111.

Bollen, K., and Lennox, R. "Conventional Wisdom on Measurement: A Structural Equation Perspective," Psychological Bulletin (110:2), 1991, pp. 305-314.
Boudreau, M.-C., Gefen, D., and Straub, D. W. "Validation in Information Systems Research: A State-of-the-Art Assessment," MIS Quarterly (25:1), March 2001, pp. 1-26.

Brown, S. A., and Venkatesh, V. "Model of Adoption of Technology in Households: A Baseline Model Test and Extension Incorporating Household Life Cycle," MIS Quarterly (29:3), September 2005, pp. 399-425.

Chin, W. W. "Issues and Opinion on Structural Equation Modeling," MIS Quarterly (22:1), March 1998a, pp. vii-xvi.

Chin, W. W. "The Partial Least Squares Approach to Structural Equation Modeling," in Modern Business Research Methods, G. A. Marcoulides (ed.), Lawrence Erlbaum Associates, Mahwah, NJ, 1998b.

Chin, W. W. "Partial Least Squares is to LISREL as Principle Components Analysis is to Common Factor Analysis," Technology Studies (2), 1995, pp. 315-319.

Chwelos, P., Benbasat, I., and Dexter, A. S. "Empirical Test of an EDI Adoption Model," Information Systems Research (12:3), September 2001, pp. 304-321.

Cohen, J. Statistical Power Analysis for the Behavioral Sciences ( $2^{\text {nd }}$ ed. $)$, L. Erlbaum Associates, Hillsdale, NJ, 1988.

Davis, F. D. "Perceived Usefulness, Perceived Ease of Use, and User Acceptance of Information Technology," MIS Quarterly (13:3), September 1989, pp. 318-346.

Diamantopoulos, A. "The Error Term in Formative Measurement Models: Interpretation and Modeling Implications," Journal of Modeling in Management (1:1), 2006, pp. 7-17.

Diamantopoulos, A., and Siguaw, J. A. "Formative Versus Reflective Indicators in Organizational Measure Development: A Comparison and Empirical Illustration," British Journal of Management (17), 2006, pp. 263-282.

Diamantopoulos, A., and Winklhofer, H. M. "Index Construction with Formative Indicators: An Alternative to Scale Development," Journal of Marketing Research (38), May 2001, pp. 259-277.

Dubin, R. "Theory Building in Applied Areas," in Handbook of Industrial and Organizational Psychology, M. D. Dunnette (ed.), Rand McNally College Publishing Company, Chicago, 1976, pp. 17-39.

Edwards, J. R. "Multidimensional Constructs in Organizational Behavior Research: An Integrative Analytical Framework," Organizational Research Methods (4:2), April 2001, pp. 144-192.

Edwards, J. R., and Bagozzi, R. P. "On the Nature and Direction of Relationships between Constructs," Psychological Methods (5:2), 2000, pp. 155-174.

Enns, H. G., Huff, S. L., and Higgins, C. A. "CIO Lateral Influence Behaviors: Gaining Peers' Commitment to Strategic Information Systems," MIS Quarterly (27:1), March 2003, pp. 155-176.

Fleiss, J. L. "Measuring Nominal Scale Agreement among Many Raters," Psychological Bulletin (76:5), 1971, pp. 378-382.

Fornell, C., and Bookstein, F. L. "Two Structural Equation Models: LISREL and PLS Applied to Consumer Exit-Voice Theory," Journal of Marketing Research (19), November 1982, pp. 440-452.

Gattiker, T. F., and Goodhue, D. L. "What Happens After ERP Implementation: Understanding the Impact of Interdependence and Differentiation on Plant-Level Outcomes," MIS Quarterly (29:3), September 2005, pp. 559-585. 
Gefen, D., Karahanna, E., and Straub, D. W. "Trust and TAM in Online Shopping: An Integrated Model," MIS Quarterly (27:1), March 2003, pp. 51-90.

Gefen, D., Straub, D. W., and Boudreau, M.-C. "Structural Equation Modeling and Regression: Guidelines for Research Practice," Communications of the AIS (4:7), August 2000, pp. 1-79.

Hair, J. F., Anderson, R. E., and Tatham, R. L. Multivariate Data Analysis ( $3^{\text {rd }}$ ed.), Macmillian, New York, 1987.

Hall, R. J., Snell A. F., and Foust, M. S. "Item Parceling Strategies in SEM: Investigating the Subtle Effects of Unmodeled Secondary Constructs," Organizational Research Methods (2:3), 1999, pp. 233-256

Ho, V. T., Ang, S., and Straub, D. "When Subordinates Become IT Contractors: Persistent Managerial Expectations in IT Outsourcing," Information Systems Research (14:1), March 2003, pp. 66-86.

Hong, W., Thong, J. Y. L., and Tam, K. Y. "Does Animation Attract Online Users' Attention? The Effects of Flash on Information Search Performance and Perceptions," Information Systems Research (15:1), March 2004, pp. 60-86.

Howell, R. D., Breivik, E., and Wilcox, J. B. "Is Formative Measurement Really Measurement?," Psychological Methods (12:2), June 2007, pp. 238-245.

Jarvenpaa, S. L., Shaw, T. R., and Staples, D. S. "Toward Contextualized Theories of Trust: The Role of Trust in Global Virtual Teams," Information Systems Research (15:3), September 2004, pp. 250-267.

Jarvis, C. B., MacKenzie, S. B., and Podsakoff, P. M. "A Critical Review of Construct Indicators and Measurement Model Misspecification in Marketing and Consumer Research," Journal of Consumer Research (30), September 2003, pp. 199-218.

Kankanhalli, A., Tan, B. C. Y., and Wei, K.-K. "Contributing Knowledge to Electronic Knowledge Repositories: An Empirical Investigation," MIS Quarterly (29:1), March 2005, pp. 113-143.

Karimi, J., Somers, T. M., and Gupta, Y. P. "Impact of Environmental Uncertainty and Task Characteristics on User Satisfaction with Data," Information Systems Research (15:2), June 2004, pp. 175-193.

Kettinger, W. J., and Lee, C. C. "Zones of Tolerance: Alternative Scales for Measuring Information Systems Service Quality," MIS Quarterly (29:4), December 2005, pp. 607-623.

Kim, S. S., Malhotra, N. K., and Narasimhan, S. "Two Competing Perspectives on Automatic Use: A Theoretical and Empirical Comparison," Information Systems Research (16:4), December 2005, pp. 418-432.

Ko, D.-G., Kirsch, L. J., and King, W. R. "Antecedents of Knowledge Transfer from Consultants to Clients in Enterprise System Implementations," MIS Quarterly (29:1), March 2005, pp. 59-85.

Koh, C., Ang, S., and Straub, D. W. "IT Outsourcing Success: A Psychological Contract Perspective," Information Systems Research (15:4), December 2004, pp. 356-373.

Law, K., and Wong, C.-S. "Multidimensional Constructs in Structural Equation Analysis: An Illustration Using the Job Perception and Job Satisfaction Constructs," Journal of Management (25:2), 1999, pp. 143-160.

Lewis, W., Agarwal, R., and Sambamurthy, V. "Sources of Influence on Beliefs about Information Technology Use: An
Empirical Study of Knowledge Workers," MIS Quarterly (27:4), December 2003, pp. 657-678.

Lilien, G. L., Rangaswamy, A., Van Bruggen, G. H., and Starke, K. "DSS Effectiveness in Marketing Resource Allocation Decisions: Reality vs. Perception," Information Systems Research (15:3), September 2004, pp. 216-235.

Little, T. D., Cunningham, M. A., Shahar G., and Widaman, K. F. "To Parcel or Not to Parcel: Exploring the Question, Weighing the Merits," Structural Equation Modeling (9:2), 2002, pp. 151-173.

MacCallum, R. C., and Browne, M. W. "The Use of Causal Indicators in Covariance Structure Models: Some Practical Issues," Psychological Bulletin (114:3), 1993, pp. 533-541.

MacKenzie, S. B. "Opportunities for Improving Consumer Research through Latent Variable Structural Equation Modeling," Journal of Consumer Research (28), June 2001, pp. 159-166.

MacKenzie, S. B., Podsakoff, P. M., and Jarvis, C. B. "The Problem of Measurement Model Misspecification in Behavioral and Organizational Research and Some Recommended Solutions," Journal of Applied Psychology (90:4), 2005, pp. 710-730.

Majchrzak, A., Beath, C. M., Lim, R. A., and Chin, W. W. "Managing Client Dialogues During Information Systems Design to Facilitate Client Learning," MIS Quarterly (29:4), December 2005, pp. 653-672.

Majchrzak, A., Malhotra, A., and John, R. "Perceived Individual Collaboration Know-How Development Through Information Technology-Enabled Contextualization: Evidence from Distributed Teams," Information Systems Research (16:1), March 2005, pp. 9-27.

Malhotra, A., Gosain, S., and El Sawy, O. A. “Absorptive Capacity Configurations in Supply Chains: Gearing for Partner-Enabled Market Knowledge Creation," MIS Quarterly (29:1), March 2005, pp. 145-187.

Malhotra, N. K., Kim, S. S., and Agarwal, J. "Internet Users' Information Privacy Concerns (IUIPC): The Construct, the Scale, and a Causal Model," Information Systems Research (15:4), December 2004, pp. 336-355.

Mathieson, K., Peacock, E., and Chin, W. W. "Extending the Technology Acceptance Model: The Influence of Perceived User Resources," The DATA BASE for Advances in Information Systems (22:3), Summer 2001, pp. 86-112.

Moore, G. C., and Benbasat, I. "Development of an Instrument to Measure the Perception of Adopting an Information Technology Innovation," Information Systems Research (2:3), September 1991, pp. 192-221.

Nunnally, J. C. Psychometric Theory, McGraw-Hill, New York, 1967.

Nunnally, J. C. Psychometric Theory (2 ${ }^{\text {nd }}$ ed.), McGraw-Hill, New York, 1978.

Pavlou, P. A., and Gefen, D. "Building Effective Online Marketplaces with Institution-Based Trust," Information Systems Research (15:1), March 2004, pp. 37-59.

Pavlou, P. A., and Gefen, D. "Psychological Contract Violation in Online Marketplaces: Antecedents, Consequences, and Moderating Role," Information Systems Research (16:4), December 2005, pp. 372-399. 
Rai, A., Patnayakuni, R., and Seth, N. "Firm Performance Impacts of Digitally Enabled Supply Chain Integration Capabilities," MIS Quarterly (30:2), June 2006, pp. 225-246.

Ravichandran, T., and Rai, A. "Quality Management in Systems Development: An Organizational System Perspective," MIS Quarterly (24:3), September 2000, pp. 381-415.

Ray, G., Muhanna, W., and Barney, J. B. "Performance of the Customer Service Process: A Resource-Based Analysis," MIS Quarterly (29:4), December 2005, pp. 625-652.

Rigdon, E. E. "A Necessary and Sufficient Identification Rule for Structural Models Estimated in Practice," Multivariate Behavior Research (30:3), 1995, pp. 359-383.

Rossiter, J. R. "The C-OAR-SE Procedure for Scale Development in Marketing," International Journal of Research in Marketing (19), 2002, pp. 305-335.

Roux, A. V. D. "A Glossary for Multilevel Analysis," Journal of Epidemiology and Community Health (56:8), August 2002, pp. 588-594.

Serva, M. A., Benamati, J. S., and Fuller, M. A. "Trustworthiness in B2C e-Commerce: An Examination of Alternative Models," The DATA BASE for Advances in Information Systems (36:3), Summer 2005, pp. 89-108.

Shadish, W. R., Cook, T. D., and Campbell, D. T. Experimental and Quasi-Experimental Designs for Generalized Causal Inference Houghton Mifflin Company, Boston, 2001.

Sivo, S. A., Saunders, C., Chang, Q., and Jiang, J. J. "How Low Should You Go? Low Response Rates and the Validity of Inference in IS Questionnaire Research," Journal of the Association for Information Systems (7:6), June 2006, pp. 351-414.

Storey, V. C., Straub, D. W., Stewart, K. A., and Welke, R. J. "A Conceptual Investigation of the E-Commerce Industry," Communications of the ACM (43:7), July 2000, pp. 117-127.

Straub, D., Boudreau, M.-C., and Gefen, D. "Validation Guidelines for IS Positivist Research," Communications of the AIS (13:24), 2004, pp. 380-427.

Straub, D. W., and Burton-Jones, A. "Veni, Vidi, Vici: Breaking the TAM Logjam," Journal of the AIS, (8:4, April), 2007, pp. 223-229.

Subramani, M. "How Do Suppliers Benefit from Information Technology Use in Supply Chain Relationships," MIS Quarterly (28:1), March 2004, pp. 45-73.

Sussman, S. W., and Siegal, W. S. "Informational Influence in Organizations: An Integrated Approach to Knowledge Adoption," Information Systems Research (14:1), March 2003, pp. 47-65.

Teo, H. H., Wei, K. K., and Benbasat, I. "Predicting Intention to Adopt Interorganizational Linkages: An Institutional Perspective," MIS Quarterly (27:1), March 2003, pp. 19-49.

Trochim, W. The Research Methods Knowledge Base (2 ${ }^{\text {nd }}$ ed.), Atomic Dog Publishing, Cincinnati, OH, 2000.

van der Heijden, H. "User Acceptance of Hedonic Information Systems," MIS Quarterly (28:4), December 2004, pp. 695-704.

Venkatesh, V., Morris, M. G., Davis, G. B., and Davis, F. D. "User Acceptance of Information Technology: Toward a Unified View," MIS Quarterly (27:3), September 2003, pp. 425-578.

Wasko, M. M., and Faraj, S. "Why Should I Share? Examining Social Capital and Knowledge Contribution in Electronic Networks of Practice," MIS Quarterly (29:1), March 2005, pp. 36-67.
Wixom, B. H., and Todd, P. A. "A Theoretical Integration of User Satisfaction and Technology Acceptance," Information Systems Research (16:1), March 2005, pp. 85-102.

Wixom, B. H., and Watson, H. J. "An Empirical Investigation of the Factors Affecting Data Warehousing Success," MIS Quarterly (25:1), March 2001, pp. 17-38.

Wold, H. "Partial Least Squares," in Encyclopedia of Statistical Sciences, S. Kotz and N. L. Johnson (eds.), Wiley, New York, 1985, pp. 581-591.

Yi, M. Y., and Davis, F. D. "Developing and Validating an Observational Learning Model of Computer Software Training and Skill Acquisition," Information Systems Research (14:2), June 2003, pp. 146-169.

\section{About the Authors}

Stacie Petter is an assistant professor at the University of Nebraska at Omaha and has published her research in outlets such as IT Professional, Computing Letters, Blackwell Encyclopedia of Management, and the Hawaii International Conference on System Sciences. Prior to obtaining her Ph.D. from Georgia State University, Stacie was a senior consultant in an IT consulting firm, an application developer, and help desk manager. Her research interests include practitioner-oriented issues such as software project management, knowledge management, and information systems success.

Detmar Straub is the J. Mack Robinson Distinguished Professor of IS at Georgia State University. He conducts research in the areas of Net-enhanced organizations, computer security, technological innovation, international IT, and research methodology. He holds a DBA (MIS; Indiana), and a Ph.D. (English; Penn State). He has 145 publications in journals including MIS Quarterly, Management Science, Information Systems Research, Organization Science, Journal of Management Information Systems, Journal of the AIS, Information \& Management, Communications of the AIS, IEEE Transactions, OMEGA, Communications of the ACM, and Sloan Management Review. Currently a senior editor for MIS Quarterly and DATA BASE, he has served as a senior editor for journals such as Information Systems Research and Journal of the AIS. Former vice president of Publications for AIS, he has served as co-program chair for the Americas Conference on Information Systems and the International Conference on Information Systems.

Arun Rai is Regents' Professor and the Harkins Chair in the Center for Process Innovation and the Department of Computer Information Systems at Georgia State University. His research has been published in MIS Quarterly, Decision Sciences, European Journal of Operations Research, IEEE Transactions on Engineering Management, Information Systems Research, Journal of Management Information Systems, and other journals. He currently serves as senior editor for Information Systems Research and associate editor for Management Science. He has also served as a senior editor for the Journal of Strategic Information Systems and on the editorial boards for Decision Sciences, IEEE Transactions on Engineering Management, Information Systems Research, Journal of the AIS, MIS Quarterly, and others. His research has been sponsored by leading corporations, including A. T. Kearney, Bozell Worldwide, DaimlerChrysler, Gartner, IBM, Intel, UPS, and SAP, among others. 


\section{Appendix A}

\section{Monte Carlo Simulations}

\section{Potential for Type II Error}

In their article, Jarvis et al. (2003) create an extensive logical and empirical argument for the use of formative measures. As part of the empirical argument for the use of formative constructs, Jarvis et al. conduct a Monte Carlo simulation to illustrate the problems that arise in the structural model when formative constructs are misspecified as reflective. The model structure used the marketing literature as a guide. All of the models in the simulation had five constructs (one exogenous and four endogenous constructs) and each of the constructs had four indicators. The error terms, path significance, and sample size were based on models typically found within the marketing literature. Jarvis et al. created two series of models. One series of models consisted of a formative exogenous construct with inter-item correlations among the formative measures varied at $0.1,0.4$, and 0.7 . The second series of models had an endogenous formative construct with inter-item correlations among the formative measures at $0.1,0.4$, and 0.7 . Figure A1 shows the parameter values and models used in the simulation by Jarvis et al.

To conduct the simulations, Jarvis et al. used EQS 5.7b. Each simulation generated a sample set of data of 500 cases and 500 data sets were used to derive the results. The authors ran simulations on both series of models with formative constructs, and then the authors performed the simulations again, but did so with the formative constructs misspecified as reflective. The authors examined the goodness of fit statistics as well as the parameter estimates. Jarvis et al. concluded that the misspecification of formative constructs as reflective created a large degree of bias in the structural paths ranging from -88 percent up to 555 percent, which suggest that Type I or Type II errors could occur due to model misspecification. However, the authors noted that it was difficult to detect if the model was misspecified using the goodness of fit statistics. Although in many cases of model misspecification, the chi-square statistic and the goodness of fit index (GFI) were not within desired ranges, the CFI, SRMR, and RMSEA showed acceptable fit, even for the misspecified models.

Although Jarvis et al. did note a large amount of bias that could occur in the structural model, the authors did not state whether or not this bias would affect the statistical significance of the structural paths. While the misspecification of the model affected the accuracy of the parameter estimates, there is no discussion regarding the significance of the paths. If the significance of the paths is affected when a formative construct is misspecified, the ramifications are such that the empirical analysis would lead to incorrect theoretical conclusions. Therefore, the simulation performed by Jarvis et al. was replicated as part of this research to evaluate when the bias was large enough to create Type I and Type II errors.

Each of Jarvis et al.'s models in Figure A1 were replicated (and extended) in the current study using EQS 6.1. The same parameters and sample sizes they used were tested in this simulation. ${ }^{14}$ The original Jarvis et al. simulation only examined a sample size of 500, which is common in the marketing literature. Given that sample sizes in the IS literature tend to be smaller, we ran additional simulations using a sample size of 250. Similar to the findings of Jarvis et al., the replication revealed similar degrees of bias in the parameter estimates; however, instead of being solely concerned with the accuracy of the estimates, we also assessed the significance of each of the structural paths. In both series of correctly specified formative models, all of the parameter estimates were significant. In both this study and in the replication, the misspecified models, which had an exogenous formative construct, and the parameter estimates for the paths emanating from the formative construct were biased upward by 300 percent or more; because these paths were significant in the correctly specified formative models, the misspecification did not cause any change in the statistical significance for any of the structural paths. For the misspecified models with an endogenous formative construct (Incorrectly Specified Models 2A - 2C), the structural path leading to the formative construct was biased downward approximately 90 percent. When the inter-item correlations among the measures of the formative construct were high (i.e., 0.7 ) or if the sample size was smaller (i.e., 250) and the inter-item correlations were moderate (i.e., 0.4), the downward bias was large enough to generate a Type II error. The path leading to the misspecified formative construct was no longer significant. Table A1 contains the parameter estimate, standard error, and t-values for each of the model parameters.

Although Jarvis et al. stated that it was possible for Type I or Type II errors to occur due to biased parameter estimates for misspecified formative models, the replication of the Jarvis et al. simulation suggests that endogenous formative constructs that are misspecified are subject to Type II error, particularly if the measures of the formative construct have high inter-item correlations.

\footnotetext{
${ }^{14}$ To ensure the replication was identical to that performed by Jarvis et al., Dr. Cheryl Jarvis was contacted to obtain the covariance matrices used in the analysis as well as a sample of the model file used in EQS. This replication used the same procedures and same seed for data generation as what was used in Jarvis et al. The only discernable difference between the updated simulation and the one performed by Jarvis and her colleagues is that a newer version of EQS was used to conduct the replication.
} 


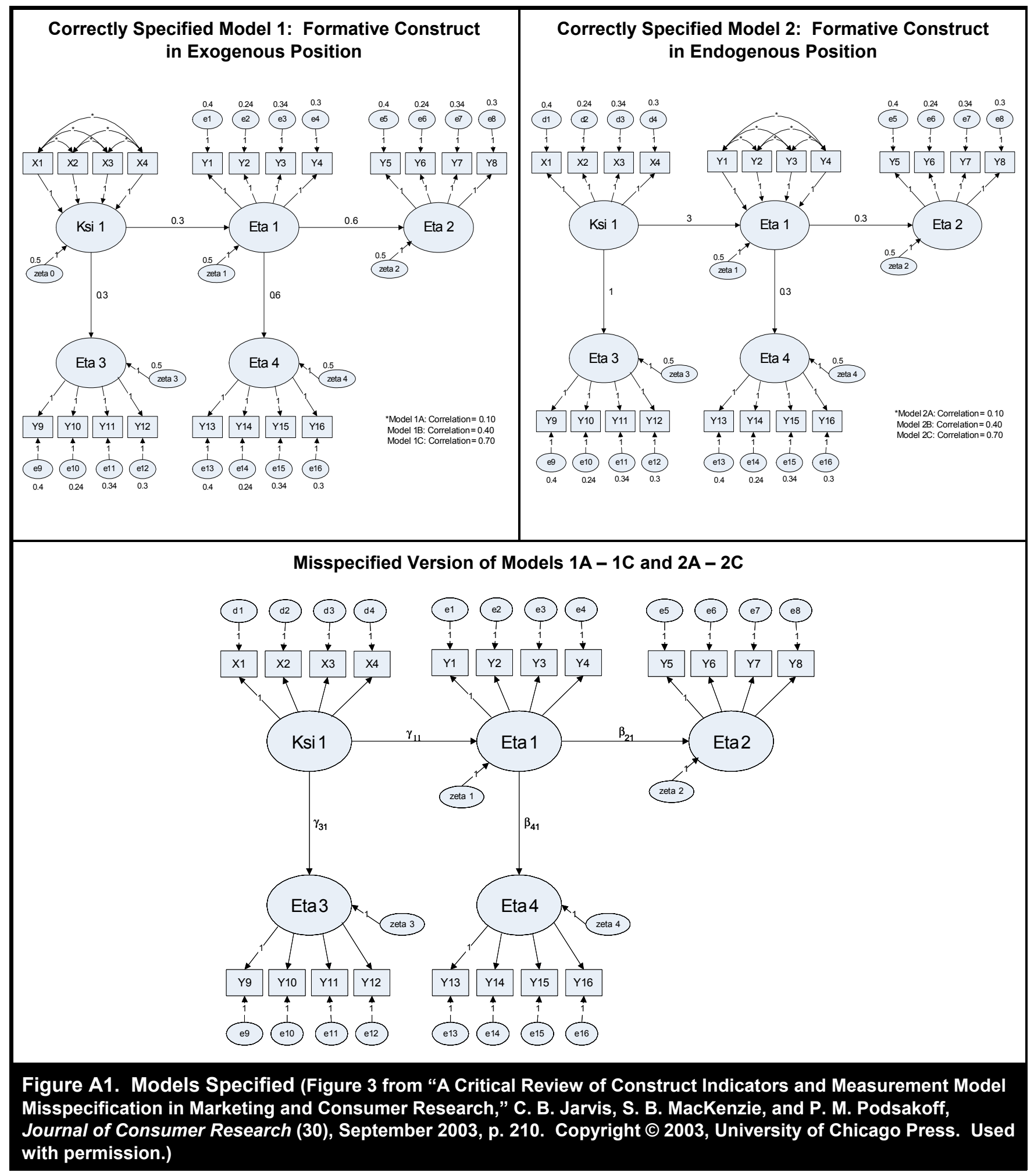




\begin{tabular}{|c|c|c|c|c|c|c|c|c|c|}
\hline \multirow[b]{2}{*}{ Specification } & \multirow{2}{*}{$\begin{array}{c}\text { Sample } \\
\text { Size }\end{array}$} & \multicolumn{2}{|c|}{ Gamma11 } & \multicolumn{2}{|c|}{ Gamma31 } & \multicolumn{2}{|c|}{ Beta21 } & \multicolumn{2}{|c|}{ Beta31 } \\
\hline & & Est & SE (t-value) & Est & SE (t-value) & Est & SE (t-value) & Est & $\overline{\text { SE (t-value) }}$ \\
\hline 1a-Correctly Specified & 250 & 0.24 & $0.03(7.24)$ & 0.24 & $0.03(7.21)$ & 0.67 & $0.07(9.92)$ & 0.56 & $0.06(9.87)$ \\
\hline 1a-Correctly Specified & 500 & 0.24 & $0.02(10.27)$ & 0.24 & $0.02(10.27)$ & 0.67 & $0.05(13.94)$ & 0.56 & $0.04(13.96)$ \\
\hline 1a-Incorrectly Specified & 250 & 1.81 & $0.33(5.48)$ & 1.77 & $0.32(5.48)$ & 0.60 & $0.06(9.90)$ & 0.60 & $0.06(9.87)$ \\
\hline 1a - Incorrectly Specified & 500 & 1.75 & $0.22(7.95)$ & 1.74 & $0.22(7.95)$ & 0.60 & $0.04(13.94)$ & 0.60 & $0.04(13.94)$ \\
\hline 1b-Correctly Specified & 250 & 0.20 & $0.03(6.63)$ & 0.20 & $0.03(6.61)$ & 0.76 & $0.07(11.33)$ & 0.57 & $0.05(11.30)$ \\
\hline $1 b-$ Correctly Specified & 500 & 0.20 & $0.02(9.44)$ & 0.20 & $0.02(9.44)$ & 0.75 & $0.05(15.94)$ & 0.57 & $0.04(15.95)$ \\
\hline $1 b-$ Incorrectly Specified & 250 & 1.47 & $0.15(9.81)$ & 1.46 & $0.15(9.77)$ & 0.60 & $0.05(11.32)$ & 0.60 & $0.05(11.31)$ \\
\hline $1 b-$ Incorrectly Specified & 500 & 1.45 & $0.10(13.95)$ & 1.45 & $0.10(13.93)$ & 0.60 & $0.04(15.95)$ & 0.60 & $0.04(15.98)$ \\
\hline 1c-Correctly Specified & 250 & 0.18 & $0.04(4.99)$ & 0.18 & $0.04(4.97)$ & 0.83 & $0.07(12.56)$ & 0.58 & $0.05(12.53)$ \\
\hline 1c-Correctly Specified & 500 & 0.18 & $0.03(7.13)$ & 0.18 & $0.03(7.12)$ & 0.82 & $0.05(17.70)$ & 0.58 & $0.03(17.71)$ \\
\hline 1c-Incorrectly Specified & 250 & 1.32 & $0.09(14.64)$ & 1.31 & $0.09(14.58)$ & 0.60 & $0.05(12.55)$ & 0.60 & $0.05(12.55)$ \\
\hline 1c-Incorrectly Specified & 500 & 1.31 & $0.06(20.73)$ & 1.31 & $0.06(20.72)$ & 0.60 & $0.03(17.69)$ & 0.60 & $0.03(17.74)$ \\
\hline $2 a-$ Correctly Specified & 250 & 3.78 & $1.07(3.54)$ & 1.26 & $0.34(3.69)$ & 0.20 & $0.03(6.99)$ & 0.20 & $0.03(7.00)$ \\
\hline 2a-Correctly Specified & 500 & 3.78 & $0.73(5.14)$ & 1.24 & $0.23(5.33)$ & 0.20 & $0.02(9.90)$ & 0.20 & $0.02(9.88)$ \\
\hline $2 a-$ Incorrectly Specified & 250 & 0.37 & $0.16(2.40)$ & 1.03 & $0.29(3.57)$ & 1.98 & $0.37(5.41)$ & 1.96 & $0.36(5.40)$ \\
\hline $2 a-$ Incorrectly Specified & 500 & 0.35 & $0.10(3.36)$ & 1.01 & $0.20(5.15)$ & 1.95 & $0.25(7.83)$ & 1.95 & $0.25(7.83)$ \\
\hline $2 b-$ Correctly Specified & 250 & 4.19 & $1.23(3.40)$ & 1.39 & $0.38(3.69)$ & 0.16 & $0.03(6.22)$ & 0.17 & $0.03(6.38)$ \\
\hline $2 \mathrm{~b}-$ Correctly Specified & 500 & 4.18 & $0.85(4.93)$ & 1.37 & $0.26(5.33)$ & 0.16 & $0.02(8.96)$ & 0.16 & $0.02(8.94)$ \\
\hline $2 b-$ Incorrectly Specified & 250 & 0.36 & $0.20(1.81)$ & 1.03 & $0.29(3.54)$ & 1.54 & $0.16(9.69)$ & 1.53 & $0.16(9.66)$ \\
\hline $2 b-$ Incorrectly Specified & 500 & 0.33 & $0.13(2.46)$ & 1.02 & $0.20(5.11)$ & 1.53 & $0.11(13.77)$ & 1.53 & $0.11(13.76)$ \\
\hline 2c-Correctly Specified & 250 & 4.64 & $1.57(2.95)$ & 1.51 & $0.41(3.68)$ & 0.14 & $0.03(4.78)$ & 0.14 & $0.03(4.78)$ \\
\hline 2c-Correctly Specified & 500 & 4.63 & $1.07(4.33)$ & 1.48 & $0.28(5.32)$ & 0.14 & $0.02(6.67)$ & 0.14 & $0.02(6.65)$ \\
\hline 2c-Incorrectly Specified & 250 & 0.24 & $0.24(1.02)$ & 1.04 & $0.29(3.52)$ & 1.34 & $0.09(14.44)$ & 1.33 & $0.09(14.37)$ \\
\hline $2 c-$ Incorrectly Specified & 500 & 0.21 & $0.16(1.29)$ & 1.02 & $0.20(5.09)$ & 1.34 & $0.07(20.42)$ & 1.33 & $0.07(20.37)$ \\
\hline
\end{tabular}

Values in bold signifiy that the path is not significant at the 0.05 level (t-value should be $>1.96$ for significance). This is evidence of Type I error.

\section{Potential for Type I Error: An Extension of Jarvis et al. (2003)}

The replication of the Jarvis et al. simulation illustrated that Type II errors could occur; however, because all of the structural parameter estimates in the model were significant, the simulations performed by Jarvis et al. cannot test the possibility of Type I errors. To determine if Type I errors could occur due to mismodeling a formative constructs as reflective, a second series of Monte Carlo simulations were performed. The same models and values used by Jarvis et al. were employed to assess the potential for Type I errors. The only change to this series of simulations is the addition of a nonsignificant path emanating from the formative constructs (Gamma 31 with a parameter estimate of 0.03$)$.

Figure A2 shows the models analyzed for this series of simulations. Exactly 500 data sets were generated for each model. Identical to Jarvis et al., one series of models contained an exogenous formative construct with inter-item correlations at $0.1,0.4$, and 0.7 (Models $3 \mathrm{~A}-3 \mathrm{C}$ ). The second series of models placed the formative construct endogenously with inter-item correlations at $0.1,0.4$, and 0.7 (Models $4 \mathrm{~A}-4 \mathrm{C}$ ). Then, to determine what happens to the parameter estimates when formative constructs are misspecified as reflective, the two series of models were simulated again, but with all reflective constructs.

This simulation also revealed similar patterns of bias in the structural parameter estimates as that of Jarvis et al. (2003). Table A2a and A2b show the resulting parameter estimates, standard errors, and t-values from the simulations. For paths emanating from the misspecified exogenous formative constructs, the parameter estimates were biased upward. Because one of the emanating paths from the formative construct in Models 1 A - 1C was nonsignificant, it was possible to determine if the upward bias would cause Type I errors to occur. For the three models with the mispecified exogenous formative construct, the bias in the parameter estimate was large; however, the standard error also increased for these parameters as well. Therefore, the significance of the parameter estimate remained nonsignificant, illustrating that a Type I error is not likely to occur in exogenous formative constructs.

Type I errors did occur, however, when the misspecified formative construct was endogenous within the structural model. The nonsignificant path emanating from the formative construct (Gamma 31) became significant when the sample size was large (i.e., 500), regardless if the formative construct was correctly specified or not. An interesting note in Table A2b, when a Type I error occurred for the correctly specified formative construct, the parameter estimate had no practical significance. The parameter estimate is accurate (i.e., 0.03), but the standard error is slightly biased downward. Researchers specifying formative constructs and finding statistically significant relationships when the parameter estimates are low should be wary if the other conditions for Type I errors stated in Table 1 are present. 


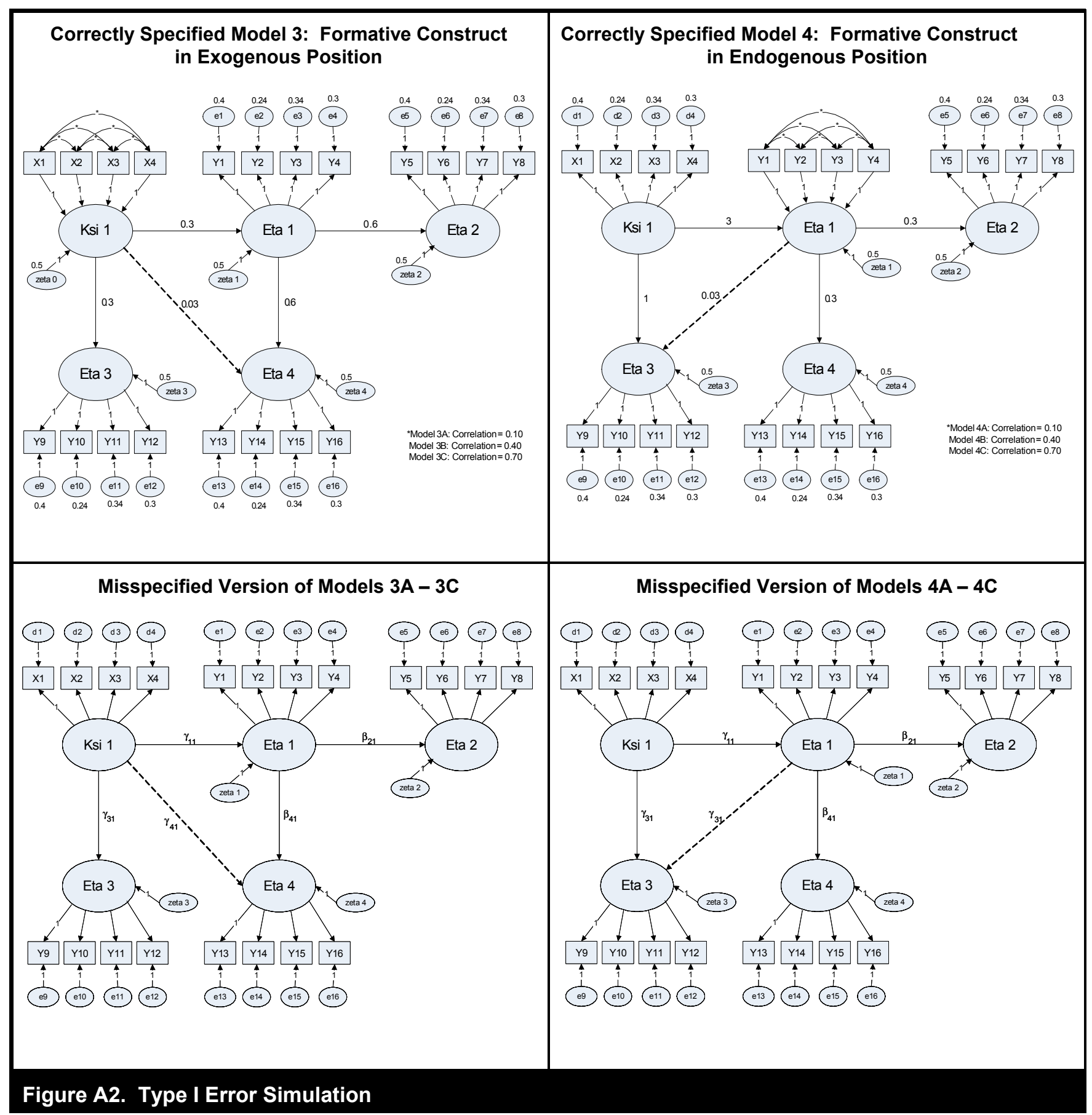




\section{Table A2. Jarvis et al. Replications}

A. Statistical Significance of Parameter Estimates for Exogenous Formative Construct

\begin{tabular}{|c|c|c|c|c|c|c|c|c|c|c|c|}
\hline \multirow[b]{2}{*}{ Specification } & \multirow{2}{*}{$\begin{array}{c}\text { Sample } \\
\text { Size }\end{array}$} & \multicolumn{2}{|c|}{ Gamma11 } & \multicolumn{2}{|c|}{ Gamma31 } & \multicolumn{2}{|c|}{ *Gamma41 } & \multicolumn{2}{|c|}{ Beta21 } & \multicolumn{2}{|c|}{ Beta41 } \\
\hline & & Est & SE (t-value) & Est & SE (t-value) & Est & SE (t-value) & Est & SE (t-value) & Est & SE (t-value) \\
\hline 3a-Correctly Specified & 250 & 0.24 & $0.03(7.28)$ & 0.24 & $0.03(7.24)$ & 0.02 & $0.02(0.96)$ & 0.67 & $0.07(9.91)$ & 0.54 & $0.08(6.89)$ \\
\hline 3a-Correctly Specified & 500 & 0.24 & $0.02(10.31)$ & 0.25 & $0.02(10.32)$ & 0.02 & $0.02(1.31)$ & 0.67 & $0.05(13.95)$ & 0.55 & $0.06(9.97)$ \\
\hline $\begin{array}{l}\text { 3a-Incorrectly } \\
\text { Specified }\end{array}$ & 250 & 1.81 & $0.33(5.50)$ & 1.76 & $0.32(5.51)$ & 0.25 & $0.31(0.81)$ & 0.60 & $0.06(9.90)$ & 0.57 & $0.12(4.69)$ \\
\hline $\begin{array}{l}\text { 3a-Incorrectly } \\
\text { Specified }\end{array}$ & 500 & 1.75 & $0.22(7.97)$ & 1.73 & $0.22(7.97)$ & 0.22 & $0.19(1.14)$ & 0.60 & $0.04(13.94)$ & 0.58 & $0.08(7.31)$ \\
\hline 3b-Correctly Specified & 250 & 0.20 & $0.03(6.66)$ & 0.21 & $0.03(6.65)$ & 0.02 & $0.02(1.06)$ & 0.76 & $0.07(11.32)$ & 0.55 & $0.08(7.02)$ \\
\hline 3b-Correctly Specified & 500 & 0.20 & $0.02(9.48)$ & 0.21 & $0.02(9.49)$ & 0.02 & $0.01(1.44)$ & 0.75 & $0.05(15.95)$ & 0.55 & $0.05(10.16)$ \\
\hline $\begin{array}{l}\text { 3b-Incorrectly } \\
\text { Specified }\end{array}$ & 250 & 1.47 & $0.15(9.81)$ & 1.45 & $0.15(9.78)$ & 0.18 & $0.18(1.01)$ & 0.60 & $0.05(11.32)$ & 0.58 & $0.10(5.63)$ \\
\hline $\begin{array}{l}\text { 3b - Incorrectly } \\
\text { Specified }\end{array}$ & 500 & 1.45 & $0.10(13.97)$ & 1.44 & $0.10(13.94)$ & 0.18 & $0.13(1.39)$ & 0.60 & $0.04(15.95)$ & 0.58 & $0.07(8.15)$ \\
\hline $3 \mathrm{c}-$ Correctly Specified & 250 & 0.18 & $0.04(5.01)$ & 0.19 & $0.04(5.00)$ & 0.02 & $0.02(1.09)$ & 0.83 & $0.07(12.59)$ & 0.54 & $0.08(7.10)$ \\
\hline $3 c-$ Correctly Specified & 500 & 0.18 & $0.03(7.16)$ & 0.19 & $0.03(7.16)$ & 0.02 & $0.01(1.50)$ & 0.83 & $0.05(17.78)$ & 0.55 & $0.05(10.28)$ \\
\hline $\begin{array}{l}3 c-\text { Incorrectly } \\
\text { Specified }\end{array}$ & 250 & 1.31 & $0.09(14.64)$ & 1.31 & 0.09 (14.59) & 0.15 & $0.14(1.13)$ & 0.60 & $0.05(12.55)$ & 0.59 & $0.09(6.46)$ \\
\hline $\begin{array}{l}\text { 3c-Incorrectly } \\
\text { Specified }\end{array}$ & 500 & 1.31 & $0.06(20.73)$ & 1.31 & $0.06(20.72)$ & 0.15 & $0.10(1.54)$ & 0.60 & $0.03(17.69)$ & 0.59 & $0.06(9.25)$ \\
\hline
\end{tabular}

\section{B. Statistical Significance of Parameter Estimates for Endogenous Formative Construct}

\begin{tabular}{|c|c|c|c|c|c|c|c|c|c|c|c|}
\hline \multirow[b]{2}{*}{ Specification } & \multirow{2}{*}{$\begin{array}{c}\text { Sample } \\
\text { Size }\end{array}$} & \multicolumn{2}{|c|}{ Gamma11 } & \multicolumn{2}{|c|}{ Gamma31 } & \multicolumn{2}{|c|}{ Beta21 } & \multicolumn{2}{|c|}{ *Beta31 } & \multicolumn{2}{|r|}{ Beta41 } \\
\hline & & Est & SE (t-value) & Est & SE (t-value) & Est & SE (t-value) & Est & SE (t-value) & Est & SE (t-value) \\
\hline 4a-Correctly Specified & 250 & 3.77 & $1.09(3.45)$ & 1.25 & $0.36(3.46)$ & 0.20 & $0.03(6.97)$ & 0.03 & $0.02(1.34)$ & 0.20 & $0.03(6.98)$ \\
\hline $4 a-$ Correctly Specified & 500 & 3.75 & $0.75(5.01)$ & 1.23 & $0.25(5.01)$ & 0.20 & $0.02(9.87)$ & 0.03 & $0.02(1.84)$ & 0.20 & $0.02(9.85)$ \\
\hline $\begin{array}{l}\text { 4a-Incorrectly } \\
\text { Specified }\end{array}$ & 250 & 0.37 & $0.16(2.30)$ & 1.08 & $0.32(3.35)$ & 1.97 & $0.36(5.42)$ & 0.17 & $0.16(1.09)$ & 1.96 & $0.36(5.40)$ \\
\hline $\begin{array}{l}\text { 4a-Incorrectly } \\
\text { Specified }\end{array}$ & 500 & 0.35 & $0.11(3.20)$ & 1.05 & $0.22(4.87)$ & 1.94 & $0.25(7.85)$ & 0.17 & $0.11(1.59)$ & 1.94 & $0.25(7.85)$ \\
\hline $4 b-$ Correctly Specified & 250 & 4.17 & $1.25(3.32)$ & 1.38 & $0.39(3.52)$ & 0.17 & $0.03(6.35)$ & 0.03 & $0.02(1.68)$ & 0.17 & $0.03(6.36)$ \\
\hline 4b-Correctly Specified & 500 & 4.17 & $0.86(4.82)$ & 1.36 & $0.27(5.08)$ & 0.17 & $0.02(8.94)$ & $\underline{0.03}$ & $0.01(2.36)$ & 0.16 & $0.02(8.91)$ \\
\hline $\begin{array}{l}4 b-\text { Incorrectly } \\
\text { Specified }\end{array}$ & 250 & 0.36 & $0.21(1.73)$ & 1.09 & $0.32(3.44)$ & 1.54 & $0.16(9.70)$ & 0.14 & $0.09(1.57)$ & 1.53 & $0.16(9.66)$ \\
\hline $\begin{array}{l}\text { 4b - Incorrectly } \\
\text { Specified }\end{array}$ & 500 & 0.33 & $0.14(2.36)$ & 1.06 & $0.21(5.00)$ & 1.53 & $0.11(13.78)$ & $\underline{0.14}$ & $\underline{0.06(2.26)}$ & 1.53 & $0.11(13.77)$ \\
\hline 4c-Correctly Specified & 250 & 4.62 & $1.59(2.90)$ & 1.50 & $0.42(3.54)$ & 0.14 & $0.03(4.77)$ & 0.03 & $0.02(1.87)$ & 0.14 & $0.03(4.77)$ \\
\hline $4 c-$ Correctly Specified & 500 & 4.60 & $1.08(4.25)$ & 1.47 & $0.29(5.11)$ & 0.14 & $0.02(6.63)$ & $\underline{0.03}$ & $0.01(2.64)$ & 0.14 & $0.02(6.63)$ \\
\hline $\begin{array}{l}4 c-\text { Incorrectly } \\
\text { Specified }\end{array}$ & 250 & 0.25 & $0.25(0.98)$ & 1.11 & $0.32(3.50)$ & 1.34 & $0.09(14.44)$ & 0.13 & $0.07(1.94)$ & 1.33 & $0.09(14.39)$ \\
\hline $\begin{array}{l}\text { 4c-Incorrectly } \\
\text { Specified }\end{array}$ & 500 & 0.21 & $0.17(1.24)$ & 1.08 & $0.21(5.10)$ & 1.34 & $0.07(20.42)$ & $\underline{0.13}$ & $\underline{0.05(2.79)}$ & 1.33 & $0.07(20.40)$ \\
\hline
\end{tabular}

*Nonsignificant path in measurement model

Values in bold signify that the path is not significant at the 0.05 level (t-value should be $>1.96$ for significance). This is evidence of Type II error.

Values in bold/underline signify that the path is significant at the 0.05 level (t-value should be $>1.96$ for significance). This is evidence of Type I error 


\section{Appendix B}

\section{Reflective Constructs in IS}

In our assessment of the recent literature in IS published in MIS Quarterly and Information Systems Research, we identified a series of properly specified constructs in IS. Most of the correctly specified formative constructs identified in this research are already outlined in Table 4, and we do not want to reiterate them here. However, there are a large number of constructs that were properly specified as reflective that researchers should feel encouraged to use (if appropriate) in future research. We present a listing of most of these constructs here.

As stated in our earlier discussion, we used the decision rules specified by Jarvis et al. (2003) listed in Table 3 to determine if a construct was formative or reflective. If at least two-thirds of the items were consistent with the decision rules for reflective constructs we categorized the construct as reflective. Researchers using one or more of the constructs listed in Table B1 are encouraged to consider each of the items using the decision rules in Table 3 and determine for themselves if it is appropriate to specify the given construct as reflective or formative.

\section{Table B1. Properly Specified Reflective Constructs}

\begin{tabular}{|c|c|}
\hline Construct Name & Studies \\
\hline Absorptive Capacity & Ko, Kirsch, and King (2005) \\
\hline Accessibility & Karimi et al. (2004); Wixom and Todd (2005) \\
\hline Accuracy & Karimi et al. (2004); Wixom and Todd (2005) \\
\hline Affiliation & Bock et al. (2005) \\
\hline Anxiety & Venkatesh et al. (2003) \\
\hline Applications for Fun & Brown and Venkatesh (2005) \\
\hline Applications for Personal Use & Brown and Venkatesh (2005) \\
\hline Assistance & Karimi et al. (2004) \\
\hline Attitude & $\begin{array}{l}\text { Bhattacherjee and Premkumar (2004); Hong et al. (2004); Wixom and } \\
\text { Todd (2005) }\end{array}$ \\
\hline Attitude Toward Knowledge Sharing & Bock et al. (2005) \\
\hline Attitude Toward Using Technology & Venkatesh et al. (2003) \\
\hline Authorization & Karimi et al. (2004) \\
\hline Behavioral Intention & $\begin{array}{l}\text { Brown and Venkatesh (2005); Teo et al. (2003) van der Heijden (2004); } \\
\text { Venkatesh et al. (2003); Wixom and Todd (2005); }\end{array}$ \\
\hline Building Effective Interorganizational Teams & Koh, Ang \& Straub (2004) \\
\hline Clear Authority Structures & Koh, Ang \& Straub (2004) \\
\hline Clear Specifications & Koh, Ang \& Straub (2004) \\
\hline Client Learning & Majchrzak, Beath, Lim, Chen (2005a) \\
\hline Close Project Monitoring & Koh, Ang \& Straub (2004) \\
\hline Codification Effort & Kankanhalli et al. (2005) \\
\hline Commitment & Wasko and Faraj (2005) \\
\hline Communication Encoding Confidence & Ko, Kirsch, and King (2005) \\
\hline Communication Interfaces & Kim et al. (2005) \\
\hline Compatibility & Karimi et al. (2004) \\
\hline Completeness & Wixom and Todd (2005) \\
\hline Computer Self-Efficacy & Lewis et al. (2003) \\
\hline Confusion & Karimi et al. (2004) \\
\hline Cooperative Independence & Majchrzak, Beath, Lim, Chen (2005a) \\
\hline Coordination Information Exchange & Malhotra et al. (2005) \\
\hline Cost & Brown and Venkatesh (2005) \\
\hline Currency & Karimi et al. (2004); Wixom and Todd (2005); \\
\hline Customer Service (Self Assessment) & Ray et al. (2005) \\
\hline
\end{tabular}


Table B1. Properly Specified Reflective Constructs (Continued)

\begin{tabular}{|c|c|}
\hline Construct Name & Studies \\
\hline Data Quality & Gattiker and Goodhue (2005) \\
\hline Decision Alternatives Considered & Lilien et al. (2004) \\
\hline Developer Communication Quality & Majchrzak, Beath, Lim, Chen (2005a) \\
\hline Disconfirmation & Bhattacherjee and Premkumar (2004) \\
\hline Domain-Knowledge-Specificity & Subramani (2004) \\
\hline Early Cohesiveness & Jarvenpaa et al. (2004) \\
\hline Early Trust & Jarvenpaa et al. (2004) \\
\hline Ease of Use & $\begin{array}{l}\text { Brown and Venkatesh (2005); Gefen et al.. (2003); Karimi et al. (2004); } \\
\text { Lewis et al (2003); van der Heijden (2004); Wixom and Todd (2005) }\end{array}$ \\
\hline Effective Knowledge Transfer & Koh, Ang \& Straub (2004) \\
\hline Effort & Lilien et al. (2004) \\
\hline Effort Expectancy & Venkatesh et al. (2003) \\
\hline Enjoy Helping & Kankanhalli et al. (2005); Wasko and Faraj (2005); \\
\hline Environmental Dynamism & Karimi et al. (2004) \\
\hline ERP Customization & Gattiker and Goodhue (2005) \\
\hline Errors & Malhotra et al. (2004) \\
\hline Experience in General Management of IT & Bassellier et al. (2003) \\
\hline Expertise & Sussman and Siegal (2003) \\
\hline Extrinsic Motivation & Ko, Kirsch, and King (2005) \\
\hline Fear of Technological Advances & Brown and Venkatesh (2005) \\
\hline Flexibility & Karimi et al. (2004); Wixom and Todd (2005) \\
\hline Focused Attention & Hong et al. (2004) \\
\hline Format & Wixom and Todd (2005) \\
\hline Friends and Family Influence & Brown and Venkatesh (2005) \\
\hline Global Information Privacy Concern & Malhotra et al. (2004) \\
\hline Image & Kankanhalli et al. (2005) \\
\hline Improper Access & Malhotra et al. (2004) \\
\hline Improvements in Coordination & Gattiker and Goodhue (2005) \\
\hline Influence Outcome & Enns et al. (2003) \\
\hline Information Quality & Wixom and Todd (2005) \\
\hline Information Satisfaction & Wixom and Todd (2005) \\
\hline Initial Trustworthiness & Jarvenpaa et al. (2004) \\
\hline Innovativeness & Bock et al. (2005) \\
\hline Integration & Wixom and Todd (2005) \\
\hline Intention to Give Information & Malhotra et al. (2004) \\
\hline Intentions to Develop Partnership & Bassellier \& Benbasat (2004) \\
\hline Interdependence with Other Plants & Gattiker and Goodhue (2005) \\
\hline Internal Stability & Kim et al. (2005) \\
\hline Interorganizational Process Modularity & Malhotra et al. (2005) \\
\hline $\begin{array}{l}\text { Interpretation Systems for Interorganizational } \\
\text { Information }\end{array}$ & Malhotra et al. (2005) \\
\hline Intrinsic Motivation & Ko, Kirsch, and King (2005) \\
\hline Involvement & Sussman and Siegal (2003) \\
\hline IT-Business Integration & Bassellier \& Benbasat (2004) \\
\hline Knowledge Networking & Bassellier \& Benbasat (2004) \\
\hline Knowledge Self-Efficacy & Kankanhalli et al. (2005) \\
\hline Knowledge Sharing & Koh, Ang \& Straub (2004) \\
\hline
\end{tabular}




\section{Table B1. Properly Specified Reflective Constructs (Continued)}

\begin{tabular}{|c|c|}
\hline Construct Name & Studies \\
\hline Late Cohesiveness & Jarvenpaa et al. (2004) \\
\hline Late Satisfaction & Jarvenpaa et al. (2004) \\
\hline Local Management Commitment & Lewis et al. (2003) \\
\hline Locatability & Karimi et al. (2004) \\
\hline Loss of Knowledge Power & Kankanhalli et al. (2005) \\
\hline Meaning & Karimi et al. (2004) \\
\hline Organizational Responsibility & Bassellier \& Benbasat (2004) \\
\hline Overall Business Impact of ERP on the Plant & Gattiker and Goodhue (2005) \\
\hline Perceived Complexity & Teo et al. (2003) \\
\hline $\begin{array}{l}\text { Perceived Effectiveness of Credit Card } \\
\text { Guarantees }\end{array}$ & Pavlou \& Gefen (2004) \\
\hline Perceived Effectiveness of Escrow Services & Pavlou \& Gefen (2004) \\
\hline $\begin{array}{l}\text { Perceived Effectiveness of Feedback } \\
\text { Mechanism }\end{array}$ & Pavlou \& Gefen (2004) \\
\hline Perceived Enjoyment & van der Heijden (2004) \\
\hline Perceived Risk from Community of Sellers & Pavlou and Gefen $(2004 ; 2005)$ \\
\hline Performance Expectancy & Venkatesh et al. (2003) \\
\hline Personal Innovativeness with Technology & Lewis et al. (2003) \\
\hline Positive Past Experience & Pavlou and Gefen $(2004 ; 2005)$ \\
\hline Presentation & Karimi et al. (2004) \\
\hline Pretraining Motivation & Yi and Davis (2003) \\
\hline Privileged Information Exchange & Malhotra et al. (2005) \\
\hline Product Characteristics & Subramani (2004) \\
\hline Project Ownership & Koh, Ang \& Straub (2004) \\
\hline Prompt Payment & Koh, Ang \& Straub (2004) \\
\hline Pro-Sharing Norms & Kankanhalli et al. (2005) \\
\hline Psychological Contract Violation & Pavlou and Gefen (2005) \\
\hline Qualitative Overload & Ahuja \& Thatcher (2005) \\
\hline Quantitative Overload & Ahuja \& Thatcher (2005) \\
\hline Reciprocity & Kankanhalli et al. (2005); Wasko and Faraj (2005) \\
\hline Reliability & Wixom and Todd (2005) \\
\hline Reputation & Wasko and Faraj (2005) \\
\hline Responsiveness & Kettinger and Lee (2005) \\
\hline Right Data & Karimi et al. (2004) \\
\hline Right Level of Detail & Karimi et al. (2004) \\
\hline Risk Beliefs & Malhotra et al. (2004) \\
\hline Role Overload & Ho, Ang, and Straub (2003) \\
\hline Satisfaction & Bhattacherjee and Premkumar (2004) \\
\hline Self-Efficacy & Brown and Venkatesh (2005) \\
\hline Situational Normality & Gefen et al. (2003) \\
\hline Social Influence & Venkatesh et al. (2003) \\
\hline Source Credibility & Sussman and Siegal (2003) \\
\hline Standard Electronic Business Interfaces & Malhotra et al. (2005) \\
\hline Status Gains & Brown and Venkatesh (2005) \\
\hline Strategic Benefits & Subramani (2004) \\
\hline Strength of Ties with Contractors & Ho, Ang, and Straub (2003) \\
\hline Subjective Norm & Bock et al. (2005) \\
\hline
\end{tabular}


Table B1. Properly Specified Reflective Constructs

\begin{tabular}{|l|l|}
\hline \multicolumn{1}{|c|}{ Construct Name } & \multicolumn{1}{c|}{ Studies } \\
\hline Subjective Quality & Jarvenpaa et al. (2004) \\
\hline System Quality & Wixom and Todd (2005) \\
\hline System Reliability & Karimi et al. (2004) \\
\hline System Satisfaction & Wixom and Todd (2005) \\
\hline Taking Charge & Koh, Ang \& Straub (2004) \\
\hline Task Efficiency & Gattiker and Goodhue (2005) \\
\hline Task Interdependence & Karimi et al. (2004) \\
\hline Task Nonroutineness & Karimi et al (2004); Majchrzak, Malhotra, and John (2005b) \\
\hline Timeliness & Wixom and Todd (2005) \\
\hline Top Management Commitment & Lewis et al. (2003) \\
\hline Training & Karimi et al. (2004) \\
\hline Transaction Intentions & Pavlou and Gefen (2004; 2005) \\
\hline Trust in Contractors & Ho, Ang, and Straub (2003) \\
\hline Trust Propensity & Pavlou and Gefen (2004; 2005) \\
\hline Trustworthiness-Based & Sussman and Siegal (2003) \\
\hline Trying to Innovate with IT & Ahuja \& Thatcher (2005) \\
\hline Unauthorized Secondary Use & Malhotra et al. (2004) \\
\hline Usage & Kankanhalli et al. (2005) \\
\hline Usefulness & Bhattacherjee and Premkumar (2004); Gefen et al. (2003); Sussman and \\
\hline Utility for Children & Siegal (2003); van der Heijden (2004) \\
\hline Utility for Work-Related Use & Brown and Venkatesh (2005) \\
\hline Workplace Referents' Influences & Brown and Venkatesh (2005) \\
\hline & Brown and Venkatesh (2005) \\
\hline
\end{tabular}

